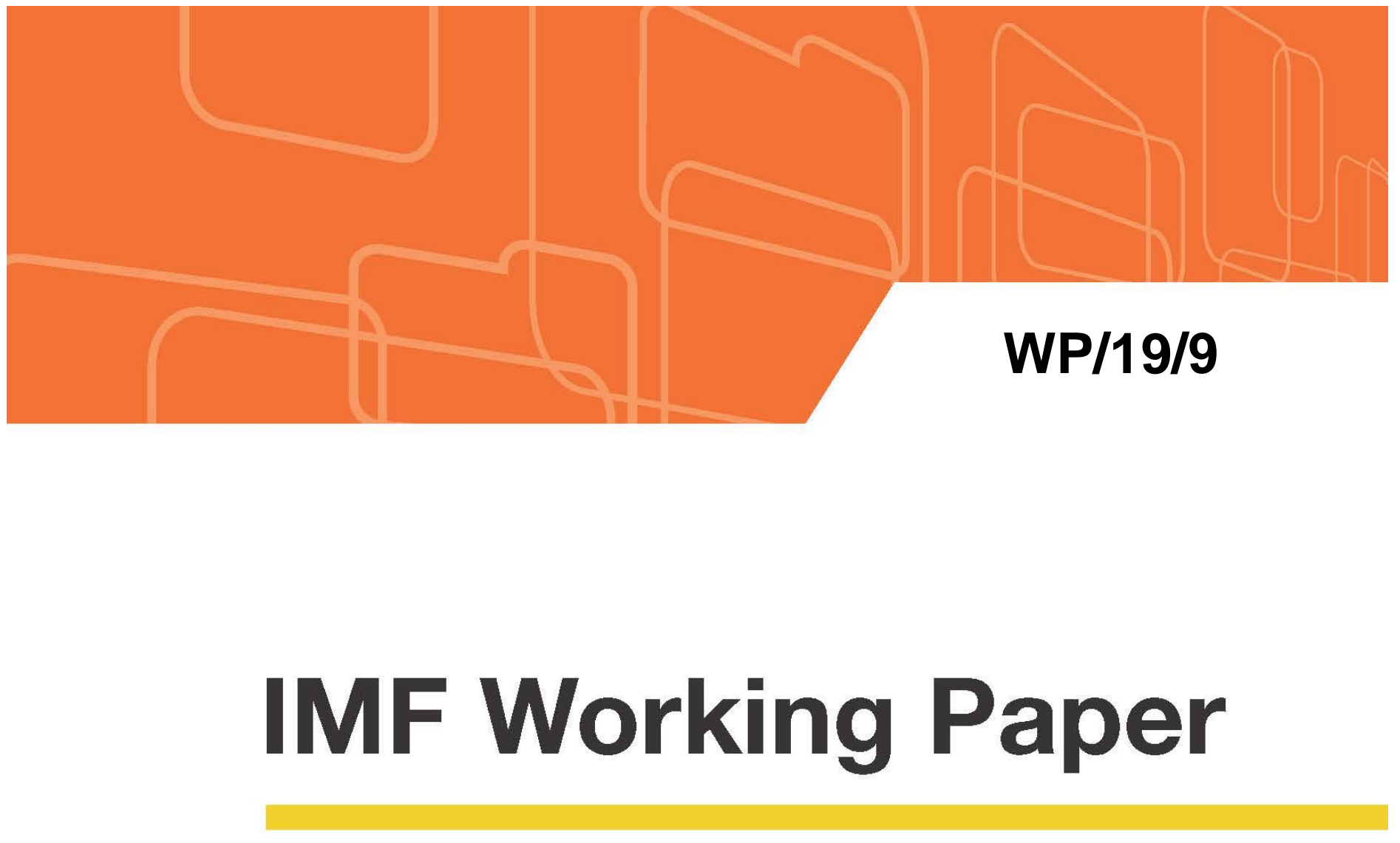

\title{
Macroeconomic Consequences of Tariffs
}

by Davide Furceri, Swarnali A. Hannan, Jonathan D. Ostry, and Andrew K. Rose

IMF Working Papers describe research in progress by the author(s) and are published to elicit comments and to encourage debate. The views expressed in IMF Working Papers are those of the author(s) and do not necessarily represent the views of the IMF, its Executive Board, or IMF management. 


\title{
IMF Working Paper
}

\author{
Research Department
}

Macroeconomic Consequences of Tariffs ${ }^{1}$

\section{Prepared by Davide Furceri, Swarnali A. Hannan, Jonathan D. Ostry, and Andrew K. Rose $^{2}$}

\author{
Authorized for distribution by Jonathan D. Ostry
}

January 2019

\begin{abstract}
IMF Working Papers describe research in progress by the author(s) and are published to elicit comments and to encourage debate. The views expressed in IMF Working Papers are those of the author(s) and do not necessarily represent the views of the IMF, its Executive Board, or IMF management.
\end{abstract}

\begin{abstract}
We study the macroeconomic consequences of tariffs. We estimate impulse response functions from local projections using a panel of annual data that spans 151 countries over 1963-2014. We find that tariff increases lead, in the medium term, to economically and statistically significant declines in domestic output and productivity. Tariff increases also result in more unemployment, higher inequality, and real exchange rate appreciation, but only small effects on the trade balance. The effects on output and productivity tend to be magnified when tariffs rise during expansions, for advanced economies, and when tariffs go up, not down. Our results are robust to a large number of perturbations to our methodology, and we complement our analysis with industry-level data.

JEL Classification Numbers: F13, O11.

Keywords: protection, output, productivity, unemployment, inequality, exchange rate, trade balance.

Author's E-Mail Address: dfurceri@imf.org, sahmed@imf.org, jostry@imf.org, arose@haas.berkeley.edu

\footnotetext{
${ }^{1}$ Key output and the data set are available at http://faculty.haas.berkeley.edu/arose. We are grateful to Charles P. De Cell and Zhangrui Wang for excellent research assistance. We would like to thank Penny K. Goldberg and the participants of the 2018 IMF Annual Research Conference for comments. This working paper is part of a research project on macroeconomic policy in low-income countries supported by U.K.'s Department for International Development. The views expressed in this paper are those of the authors and do not necessarily represent the views of the IMF, its Executive Board, or IMF management.

${ }^{2}$ Furceri and Hannan are IMF Research Department; Ostry is IMF Research Department and CEPR; Rose is Berkeley-Haas, ABFER, CEPR and NBER.
} 


\section{CONTENTS}

I. Introduction

II. Empirical Methodology _ 9

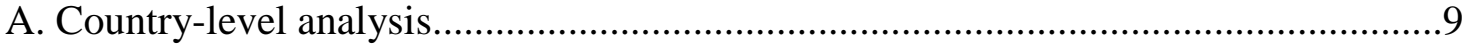

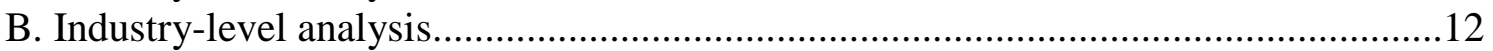

III. Results _ 14

A. Aggregate Results .................................................................................. 14

IV. Conclusion___ 27

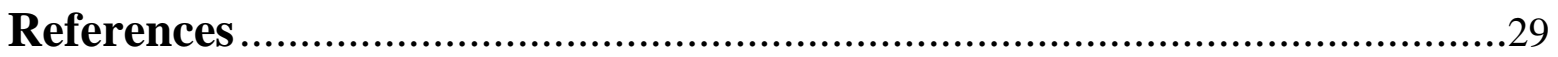

\section{List of Tables}

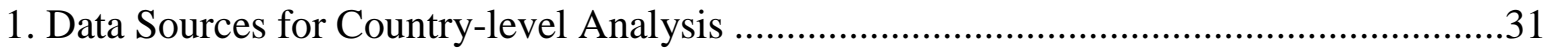

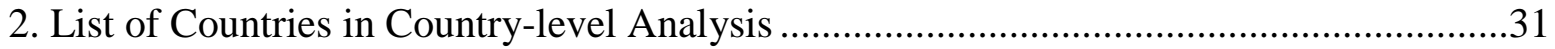

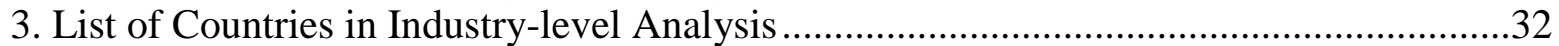

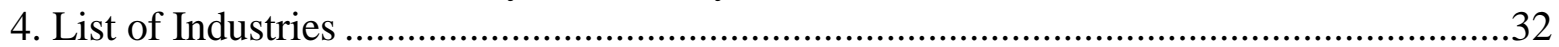

5. List of Advanced Economies in Country-level Analysis................................................33

6. The Aggregate and Distributional Effects of Tariffs ..................................................34

\section{List of Figures}

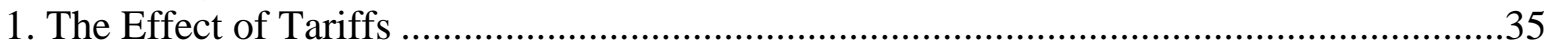

2. The Effect of Tariffs - Tariff Increases vs. Decreases; Advanced Economies vs. Emerging

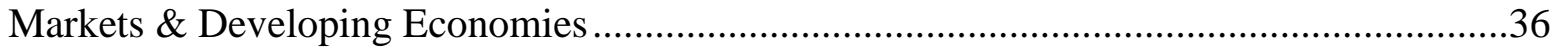

3. The Effect of Tariffs - Expansions vs. Recessions......................................................37

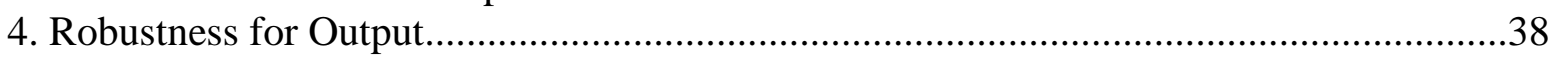

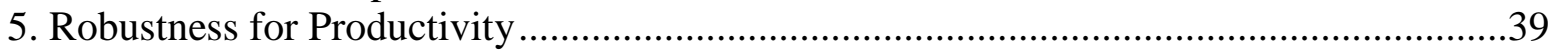

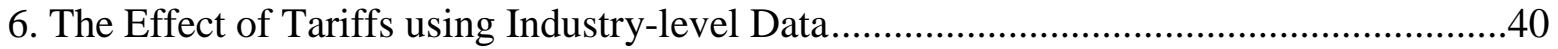

\section{Appendices}

I. Three Episodes of Tariff Hikes ...................................................................................41

II. Results for Unemployment, Inequality, Real Exchange Rate, and Trade Balance ...........43

III. Robustness Results for Unemployment, Inequality, Real Exchange Rate, and Trade

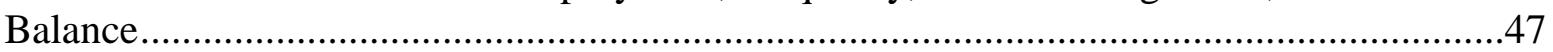

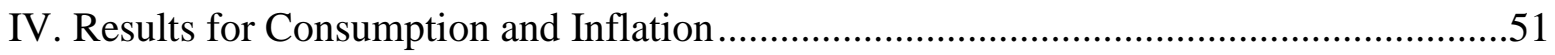

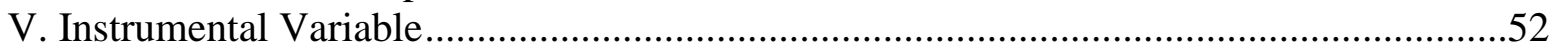

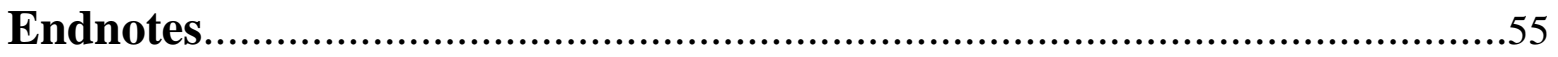




\section{INTRODUCTION}

More than on any other issue, there is agreement amongst economists that international trade should be free. ${ }^{1}$ This view dates back to (at least) Adam Smith and is supported by much reasoning. In general, economists believe that freely-functioning markets best allocate resources, at least absent some distortion, externality or other market failure; competitive markets tend to maximize output by directing resources to their most productive uses. Of course, there are market imperfections, but tariffs-taxes on importsare almost never the optimal solution to such problems. Tariffs encourage the deflection of trade to inefficient producers, and smuggling to evade tariffs; such distortions reduce welfare. Further, consumers lose more from a tariff than producers gain, so there is "deadweight loss". The redistributions associated with tariffs tend to create vested interests, so harms tend to persist. Broad-based protectionism can also provoke retaliation which adds further costs in other markets. All these losses to output are exacerbated if inputs are protected, since this adds to production costs.

Discussions of market imperfections and the like are naturally microeconomic in nature. Accordingly, most analysis of trade barriers is microeconomic in nature, focusing on individual industries (see Grossman and Rogoff (1995) and references therein). This makes sense. Artificial barriers to international trade have gradually fallen for most countries over the decades since the end of World War II. The exceptions to this trend tend to be concentrated in individual industries, often associated with agriculture or apparel. International commercial policy tends not to be used as a macroeconomic tool, probably 
because of the availability of superior alternatives such as monetary and fiscal policy. In addition, there are strong theoretical reasons that economists abhor the use of protectionism as a macroeconomic policy; for instance, the broad imposition of tariffs may lead to offsetting changes in exchange rates (Dornbusch, 1974; Edwards, 1989). And while the imposition of a tariff could reduce the flow of imports, it is unlikely to change the trade balance unless it fundamentally alters the balance of saving and investment. Further, economists think that protectionist policies helped precipitate the collapse of international trade in the early 1930s, and this trade shrinkage was a plausible seed of World War II. So, while protectionism has not been much used in practice as a macroeconomic policy (especially in advanced countries), most economists also agree that it should not be used as a macroeconomic policy.

Times change. Some economies have recently begun to use commercial policy, seemingly for macroeconomic objectives. So it seems an appropriate time to study what, if any, the macroeconomic consequences of tariffs have actually been in practice. Most of the predisposition of the economics profession against protectionism is based on evidence that is either a) theoretical, b) micro, or c) aggregate and dated. Accordingly, in this paper, we study empirically the macroeconomic effects of tariffs using recent aggregate data.

Our strategy is to use straightforward methodology that tackles the key issues headon. We use a transparent approach to allow the data to speak in a straightforward way, allowing us to focus attention on results rather than the estimation technique. We rely on Jorda's (2005) celebrated local projection method to estimate impulse response functions, 
allowing us as to account flexibly for non-linearities without imposing potentially inappropriate dynamic restrictions. ${ }^{2}$ Our panel of annual data is long if unbalanced, covering 1963 through 2014; more recent data is of greater relevance, but older data contains more protectionism. Since little protectionism remains in rich countries, we use a broad span of 151 countries, including 34 advanced and 117 developing countries.

We ask what the effects of changes in tariffs have been on a number of key variables of interest, including output, productivity, unemployment, inequality, the real exchange rate, and the trade balance. Our chief data set is aggregate in nature, but we also use sectoral data, both to probe more deeply and to check the sensitivity of our results. We also explore whether the effects of tariffs depend upon the stage of the business cycle, whether there are asymmetric effects of tariff rises and falls, whether tariff consequences are similar for countries at different stages of development, and so forth.

We study tariffs rather than other types of protectionism for three reasons. First, tariffs are the preferred protectionist policy of rich governments, past and present. Second, tariffs are easier to measure in the aggregate than non-tariff barriers. Third, we try to be conservative when possible, and the costs of tariffs are a lower bound for the costs of protectionism, since non-tariff barriers typically have more costly consequences than tariffs. $^{3}$ This conservative strategy also drives our domestic focus. For example, though we are cognizant that Canadian protectionism clearly has effects outside the Great White North, we are most interested in the consequences of Canadian tariffs for Canadian output, productivity, and so forth. 
Our results suggest that tariff increases have adverse domestic macroeconomic and distributional consequences. We find empirically that tariff increases lead to declines of output and productivity in the medium term, as well as increases in unemployment and inequality. In contrast, we do not find an improvement in the trade balance after tariffs rise, plausibly reflecting our finding that the real exchange rate tends to appreciate as a result of higher tariffs. The longer-term consequences of tariffs are likely higher than the medium-term effects that we estimate, but we truncate our analysis at the five year horizon to be conservative. Further, we perform considerable sensitivity analysis to demonstrate the robustness of our results.

The extensive time and country coverage of our dataset has a cost; we cannot control for concomitant structural policies due to an absence of data. However, the length and breadth of our dataset has a benefit; it allows us to conduct a battery of robustness checks that provide comfort about the general validity of the results. In particular, we conduct a number of robustness checks, which include: a) controlling for contemporaneous shocks in the trade balance and real exchange rates, b) controlling for expected future growth, and c) employing a VAR model where tariffs are ordered last - that is, assuming that changes in tariffs react to contemporaneous changes in economic activity. To the extent that structural policies affect output and other key macroeconomic variables, the concerns related to concomitant structural policies should be mitigated by these alternative specifications. 
We also take advantage of our panel data set to check the uniformity of our results and find interesting differences. The medium-term decline in output, following a tariff increase, tends to be more pronounced if the tariff increase is undertaken during an economic expansion. Alternatively, the tariff-induced output increase is smaller following a tariff decrease in a recession, consistent with the view that trade liberalization leads to output losses during periods of weak economic activity, since it induces inter-sectoral shifts. We also find evidence suggesting asymmetric effects of trade protectionism and liberalization; the medium-term output effects associated with a tariff increase are not symmetric to those that follow tariff reduction. Tariff increases also have more adverse effects for advanced economies than for poorer countries.

Our paper relates to several strands of the literature on the impact of trade policies. Earlier studies show that there is no theoretical presumption about the effects of tariffs on output or the trade balance, with the impact depending on a host of factors including the timing and expected duration of the tariff shock, the behavior of real wages and exchange rates, the values of various elasticities, and institutional factors like the exchange rate regime and degree of capital mobility (Ostry and Rose, 1992). More recent work has either focused on understanding the impact of trade liberalization/trade openness on currency movements and the trade balance (Santos-Paulino and Thirlwall, 2004; UNCTAD, 1999; Ju, Wu, and Zeng, 2010; Li, 2004) or on productivity and output (Feyrer, 2009; Alcala and Ciccone, 2004). The impact of trade policies on inequality has been studied in the context of debates about the relative importance of trade and technology in driving inequality (Helpman, 2016) or by using firm-level data to understand the impact of 
commercial policy on wage inequality (Artuc and McLaren, 2015; Klein, Moser, and Urban, 2010). More recently, the impact of trade policies on macroeconomic fluctuations has been studied using high-frequency trade policy data on temporary trade barriers (Barattieri, Cacciatore, and Ghironi, 2018).

Compared to this literature, the scope of our paper is ambitious in terms of the data (across both countries and time) and the number of outcome variables explored: we provide a more comprehensive picture of the macroeconomic and distributional effect of tariffs. In addition, while previous studies have looked at the impact of trade liberalization or trade openness, we look only at tariffs-a more narrow variable which may also be more relevant in the current global political context. While model simulations and theoretical studies emphasize channels and transmission mechanisms, the gains (losses) from trade (protectionism) generated by these models are often implausibly small. ${ }^{4}$ Hence, we consider a reduced-form approach that uses wide span of data to be a potentially important contribution to the literature and the current policy debate.

We emphasize that our results bolster the case for free trade and seem wholly consistent with conventional wisdom in the discipline. However, that prior is not wellgrounded in solid empirical findings, at least at the macro level; filling this gap is the chief objective of this paper. We think this new empirical benchmark helps justify the bent of the discipline towards liberal trade, which is currently based mostly on theoretical grounds, or empirical evidence that is either microeconomic or dated. 


\section{Empirical Methodology}

This section describes the empirical methodology we use to examine the dynamic response of the variables of interest (output, productivity, and so forth), to changes in tariff rates.

Our strategy is to allow the data to speak as clearly as possible, using a reducedform approach without imposing unreasonable constraints. Our focus is on the macroeconomic consequences of tariff changes, using a broad recent panel of data. We act conservatively in a number of ways, including our focus on purely domestic consequences, and our limited time horizon. Our goal is to establish a plausible set of benchmark results, and then use sensitivity analysis to show the robustness of these results.

We use two estimation frameworks. The first is more important; it is applied to country-level data and serves to quantify the macroeconomic effects of tariffs. As a robustness check, the second is applied to sector-level data, and provides insight into the channels through which the effects of tariffs are transmitted, while also addressing some of the limitation of the country-level analysis (by controlling for national macroeconomic shocks that may be correlated with tariff changes).

\section{A. Country-level analysis}

Our objective is to trace out the response of various outcome variables of interest to tariff changes. Accordingly, we use the well-known local projection method - "LPM" henceforth (Jordà, 2005) - to estimate impulse-response functions. This approach has 
been advocated by Stock and Watson (2007) and Auerbach and Gorodnichenko (2013), among others, as a flexible choice that does not impose the dynamic restrictions embedded in models like vector autoregressions or autoregressive-distributed lag specifications; it is particularly suited to estimating nonlinearities in the dynamic responses. The baseline regression is specified as follows:

$$
y_{i, t+k}-y_{i, t-1}=\alpha_{i}+\gamma_{t}+\beta \Delta T_{i, t}+v X_{i, t}+\varepsilon_{i, t}
$$

where:

- $\mathrm{y}_{\mathrm{i}, \mathrm{t}+\mathrm{k}}$ is the outcome variable of interest (log of output, productivity, unemployment rate, Gini coefficient, log real exchange rate, or trade balance/GDP) for country i at time $\mathrm{t}+\mathrm{k}$,

- $\left\{\alpha_{i}\right\}$ are country fixed effects to control for unobserved cross-country heterogeneity,

- $\left\{y_{t}\right\}$ are time fixed effects to control for global shocks,

- $\Delta T_{i, t}$ is the change in the tariff rate,

- $v$ is a vector of nuisance coefficients

- $\mathrm{X}_{\mathrm{i}, \mathrm{t}}$ is a vector of control variables, including two lags of each of: a) changes in the dependent variable, b) the tariff, c) log output, d) the log of real exchange rates and d) the trade balance in percent of GDP, and

- $\varepsilon$ is an unexplained (hopefully well-behaved) residual. 
The coefficients of greatest interest to us are $\{\beta\}$, the impulse responses of our variables of interest to changes in the tariff rate. ${ }^{5}$ We choose our variables of interest to portray arguably the four most important manifestations of the health of the real macroeconomy: GDP, productivity, the unemployment rate, and inequality (the latter measured by the Gini coefficient). We also portray two key transmission mechanisms for tariff shocks, namely the real exchange rate and the balance of trade.

\section{$\underline{\text { Data Sources }}$}

The macroeconomic series for annual GDP, labor productivity (defined as the ratio of GDP to employment), the unemployment rate, real effective exchange rates (period average, deflated by $\mathrm{CPI}$ ) and the trade balance (period average, deflated by GDP) are taken from IMF WEO and World Bank WDI databases. Data on the Gini coefficient, a measure of inequality, come from the Standardized World Income Inequality Database (SWIID). Table 1 provides a summary of our data sources.

Our tariff series, $\mathrm{T}$, is based on trade tariff rate data at the product level. The main sources are the World Integrated Trade Solution (WITS) and World Development Indicators (WDI); other data sources include: the World Trade Organization (WTO); the General Agreement on Tariffs and Trade (GATT); and the Brussels Customs Union database (BTN). We aggregate product-level tariff data by calculating weighted averages, with weights given by the import share of each product, measured as fractions of value. 
Equation (1) is estimated at the annual frequency for an unbalanced sample of 151 countries from 1964 to 2014. Table 2 provides the list of countries used in the country-level analysis.

B. Industry-level analysis

The empirical specification for industries follows the one used for the analysis on macro data:

$$
y_{j, i, t+k}-y_{j, i, t-1}=\alpha_{i j}+\gamma_{i t}+\rho_{j t}+\beta^{\prime} \Delta T_{j, j, t} t^{\prime}+\beta^{o} \Delta T_{j, i, t}{ }^{0}+v X_{j, i, t}+\varepsilon_{j, i, t}
$$

where $\mathrm{y}_{\mathrm{j}, \mathrm{i}, \mathrm{t}+\mathrm{k}}$ is the log of sectoral output (or productivity) for industry $j$ in country $i$ at time $t+k ; \gamma_{i t}$ are country-year fixed effects to control for any variation that is common to all sectors of country's economy, including, for instance, aggregate output growth or reforms in other areas; $\alpha_{\mathrm{ij}}$ are country-industry fixed effects to control for industry-specific factors, including, for instance, cross-country differences in the growth of certain sectors that could arise from differences in comparative advantages; $\rho_{\mathrm{jt}}$ are industry-time fixed effects to control for common factors across countries that can affect specific industries; $\mathrm{T}_{\mathrm{j}, \mathrm{i}, \mathrm{t}}{ }^{\mathrm{O}}$ and $\mathrm{T}_{\mathrm{j}, \mathrm{i}, \mathrm{t}}{ }^{\prime}$ denote output and input tariffs, respectively; and $\mathrm{X}_{\mathrm{j}, \mathrm{i}, \mathrm{t}}$ is a vector of control variables, including two lags of changes in the dependent variables and output and input sectoral tariffs. 
The output tariff, $\mathrm{T}_{\mathrm{j}, \mathrm{i}, \mathrm{t}}{ }^{\mathrm{O}}$ in each sector $\mathrm{j}$ is the 2-digit level corresponding tariff rate. Following closely Amiti and Konings (2007) and Topalova and Khandelwal (2011), input tariffs in each sector $\mathrm{j}$ are computed as weighted average of output tariffs in all sectors, with weights reflecting the share of imported inputs from each of these sectors used in the production of sector j's total input:

$$
T_{j, i, t}^{I}=\sum_{k} \theta_{j, i, t} T_{k, i, t}{ }^{o}
$$

The underlying tariff data is obtained from World Integrated Trade Solution (WITS), while the information on the production structure is taken from OECD's input-output tables.

We match the resulting input and output tariff rates with sectoral-level data (output, value added, employment and productivity) taken from the United Nations Industrial Development Organization (UNIDO) database. This database provides information for 22 manufacturing industries based on the INDSTAT2 2016, ISIC Revision $3 .{ }^{6}$ However, to match the sectoral information in the OECD input-output table, we combine some of the sectors in the UNIDO database. The resulting dataset comprise an unbalanced panel with 16 sectors for 39 countries over the period 1991-2014. Tables 3 and 4 provide the list of countries and sectors. 


\section{RESULTS}

\section{A. Aggregate Results}

\section{Baseline}

Our benchmark aggregate results are presented in Figure 1. Each of the six panels presents the estimated dynamic response for a variable of interest (output, productivity, and so forth) to a one-standard deviation rise in the tariff rate. This is a moderate increase in the tariff rate, of about 3.6 percentage points, that lies well within the standard range of the data. ${ }^{7}$ Collectively, the impulse response functions in Figure 1 provide a convenient way to portray the responses of key indicators of the macroeconomy to tariff shocks. Time is portrayed on the x-axes; the solid lines portray the average estimated response, and we include its 90 percent confidence interval as dotted lines (computed using Driscoll-Kraay standard errors). ${ }^{8}$ In another effort to be conservative, we truncate our results five years after the shock.

The results in Panel A suggest that a one standard deviation (or 3.6 percentage point) tariff increase leads to a decrease in output of about $.4 \%$ five years later. We consider this effect to be plausibly sized and economically significant; it is also significantly different from zero in a statistical sense. Why does output fall after a tariff increase? Panel $B$ indicates that a key channel is the statistically and economically significant decrease in labor productivity, which cumulates to about .9\% after five years. Both these key findings make eminent sense; the wasteful effects of protectionism eventually lead to a meaningful 
reduction in the efficiency with which labor is used, and thus output. ${ }^{9}$ Protectionism also leads to a small (statistically marginal) increase in unemployment, as shown in Panel C. Thus the aggregate results for real activity bolster the traditional case against protectionism. So does the evidence on distribution, shown in Panel D; we find that tariff increases lead to more inequality, as measured by the Gini index; the effect becomes statistically significant two years after the tariff change. ${ }^{10}$

To summarize: the aversion of the economics profession to the deadweight losses caused by protectionism seems warranted; higher tariffs seem to have lower output and productivity, while raising unemployment and inequality.

The bottom part of Figure 1 portrays key parts of the transmission mechanism between tariffs and the macroeconomy. As expected, higher tariffs lead to an appreciation of the real exchange rate as shown in Panel $E$, though the effect is only statistically significantly different from zero in the short term (this is unsurprising, given the noisiness of exchange rates). Panel $\mathrm{F}$ shows the net effects of higher tariffs on the trade balance are small and insignificant; absent shifts in saving or investment, commercial policy has little effect on the trade balance.

The reduced-form approach does not allow for a full-fledged analysis of the welfare effects of tariffs. However, there is certainly evidence suggestive of negative implications. For instance, apart from the negative impact on output, we find that protectionism also leads to a statistically significant decline in consumption, of around 0.4 percent after four years (Panel A of Appendix Figure AIV.1). ${ }^{11}$ 
We therefore consider our results to be reasonable and indeed comforting, at least to the mainstream of the profession; they are quite consistent with conventional wisdom. Still, it is important to examine the generality of our findings, and to see how sensitive they are to the assumptions that we have implicitly made in our analysis. We begin by examining heterogeneity, since three striking and unusual aspects of contemporary protectionism are that tariffs are a) rising, in b) advanced economies, during c) periods of economic expansion.

\section{$\underline{\text { Tariff Increases vs. Decreases }}$}

Thus far, we have implicitly assumed that tariff increases and decreases have symmetric effects. Is this assumption warranted? This is a simple matter to examine, since around $40 \%$ of our sample consists of tariff rises (with mean of $1.7 p p t$ and standard deviation of 3.3), while $53 \%$ of observations consist of tariff falls (with mean of $-1.8 p p t$ and standard deviation of 3.4). ${ }^{12}$ This variation allows us to test for asymmetry; we extend the baseline specification to allow the response to vary with the sign of the tariff change:

$$
y_{i, t+k}-y_{i, t-1}=\alpha_{i}+y_{t}+\beta^{P} D^{P}{ }_{i, t} \Delta T_{i, t}+\beta^{N}\left(1-D_{i, t}^{P_{i, t}}\right) \Delta T_{i, t}+v X_{i, t}+\varepsilon_{i, t}
$$

where $D^{P}, t$ is a binary variable which is equal to unity when the change in tariff is positive, and zero otherwise. 
We present our results on the symmetry of tariff increases and decreases in the top half of Figure 2. The left column presents impulse response functions (estimated from (2) but otherwise similar to those of Figure 1), portraying the effects of tariff increases (in the top row) and decreases (immediately below) on output. The right column is similar, but portrays the response of productivity instead of GDP; we focus on output and productivity since they are two of the most important variables that are plausibly affected by protectionism. To facilitate comparison, the dynamic responses under the assumption of symmetry (estimated with (1), and thus presented in the top row of Figure 1) are also shown as dashed lines.

Manifestly, the decline in output following a one standard deviation increase in the tariff rate is higher than the baseline; this effect is statistically significant, as shown in Panel A of Figure 2 for both output and productivity. In contrast, Panel B shows that the effects of a tariff fall on both output and productivity are much smaller. That is, there are asymmetric effects of protectionism; tariff increases hurt the economy more than liberalizations help.

One of the channels for the asymmetric effects related to tariff increases (as opposed to decreases) is due to intertemporal effects on domestic demand (Irwin, 2014). The decline in tariffs usually results in a slight, immediate increase in demand because purchasers know that lower prices will prevail in the future. On the other hand, tariff increases usually lead to an increase in buying before policy implementation, followed by a collapse afterwards. In other words, the decline in domestic demand following a positive 
tariff shock is higher than the increase in domestic demand following a negative tariff shock. This line of argument is also supported by our results on consumption, as shown in Figure AIV.1 (Panels $\mathrm{C}$ and D): tariff increases lead to a higher decline in consumption than in the baseline.

\section{Advanced Economies vs. Emerging Markets \& Developing Economies}

In exactly the same way, we explore whether the effect of tariffs depend on the income level of the country, since advanced economies tend to use protectionism less than poorer economies. ${ }^{13}$ We extend the baseline regression to test for asymmetry depending upon income level:

$$
y_{i, t+k}-y_{i, t-1}=\alpha_{i}+y_{t}+\beta^{A E} D^{A E_{i}} \Delta T_{i, t}+\beta^{O \text { th }}\left(1-D^{A E_{i}}\right) \Delta T_{i, t}+v X_{i, t}+\varepsilon_{i, t}
$$

where $D^{A E_{i}}$, is a binary variable which is equal to unity for advanced economies, and zero otherwise. The list of advanced economies follows the IMF classification and is tabulated in Table 5.

Our results appear in the bottom part of Figure 2; the impulse response functions are analogous to those in the top half (which is based on (2)), but for a different split of the data (based on equation 3). An interesting asymmetry emerges; for advanced economies, 
the decline in output after tariff increases is larger than in the baseline. Panel C shows that output declines by about $1 \%$ after four years for advanced economies, compared to the $.4 \%$ decline in the baseline over the same time horizon. Similarly, the effect on productivity is higher than in the baseline for advanced economies, but lower for other economies.

One of the reasons for the different effects in advanced and emerging/developing economies could be due to the differential impact of trade liberalization. Leibovici and Crews (2018) provide suggestive evidence that the potential gains from trade liberalization differ based on a country's income level. Factors like financial development, limited infrastructure, and limited human capital prevent EMDEs from increasing production to sell internationally following trade liberalization. Consequently, EMDEs are disproportionally less affected during trade protectionism episodes, since they reap less benefits from trade liberalization to begin with.

\section{Recessions vs. Expansions}

Does the effect of tariff changes vary with the stage of the business cycle? Trade reforms, insofar as they induce resource shifts between industries, occupations and firms, might lead to larger output losses during slack periods of weak domestic economic activity. To test whether the effect of tariff changes is symmetric between expansions and recessions, we use the following setup, which permits the effect of tariff changes to vary smoothly across different stages of the business cycle: 


$$
y_{i, t+k}-y_{i, t-1}=\alpha_{i}+y_{t}+\beta^{L}{ }_{k} F\left(z_{i, t}\right)_{i} \Delta T_{i, t}+\beta^{H}{ }_{k}\left(1-F\left(z_{i, t}\right) \Delta T_{i, t}+\phi Z_{i, t}+\varepsilon_{i, t}\right.
$$

with

$$
F\left(z_{i, t}\right)=\exp \left(-\theta z_{i, t}\right) /\left(1+\exp \left(-\theta z_{i, t}\right), \quad \theta>0,\right.
$$

where $z_{i, t}$ is an indicator of the state of the economy (such as GDP growth or unemployment) normalized to have zero mean and unit variance, and $Z_{i t}$ is the same set of control variables used in the baseline specification but now also including $F\left(z_{i t}\right) . F($.$) is a$ smooth transition function used recently by Auerbach and Gorodnichenko (2012) to estimate the macroeconomic impact of fiscal policy shocks in expansions as opposed to recessions. This transition function can be interpreted as the probability of the economy being in a recession; $F\left(z_{i t}\right)=1$ corresponds to a deep recession, while $F\left(z_{i t}\right)=0$ corresponds to strong expansion-with the cutoff between expansions and contractions being 0.5 . Like Auerbach and Gorodichencko, we use $\theta=1.5$, which corresponds to assume that the economy spends about 20 percent of times in recessions. ${ }^{14}$

The results from estimating equation (4) for output (in the left column) and productivity (on the right) are presented in Figure 3. We use two different measures of business cycle conditions; the panels at the top use GDP growth, while those below are based on the unemployment rate. For each indicator of the business cycle, impulse response functions for expansions are presented immediately above those for recessions. 
Since the results from the two different indicators of the business cycle are similar, we concentrate on the top four panels, which use GDP growth as a business cycle measure.

The results in Figure 3 suggest that the response of both output and productivity to rises in the tariff is more dramatic during expansions. When tariffs increase by a standard deviation and the economy is enjoying good times, the medium-term loss in output is higher than the baseline by about 1\%; the productivity decline is also larger. Consistently, tariff increases during recession seem to increase output and productivity in the mediumterm, though the effects are not statistically significant; protection during recessions may have a mild stimulating effect. ${ }^{15}$

Overall, we find that tariff changes have more negative consequences for output and productivity when: tariffs increase (rather than decrease); for advanced economies (not emerging markets and developing economies); and during good economic conditions. While more work needs to be done to understand the channels for these effects better, they do not bode well for the present protectionist climate. ${ }^{16}$

One of the reasons why the impact of tariffs depends on the state of the business cycle could be related to the effect of tariffs on inflation and the role of monetary policies. To the extent that the increases in tariffs lead to an increase in inflation during expansions and that monetary policies are tightened in response, the negative impact of tariffs is magnified due to the contractionary policy shock. Our results on inflation seem to support this reasoning; using the same regression-framework as for the other macroeconomic variables, we find that higher tariffs lead to an increase in inflation after two years, as 
shown in Panel B of Figure AIV.1. Furthermore, the effect on inflation is stronger during economic expansions than in recessions, as shown in Panels $E$ and $F$ of Figure AIV.1. These results are consistent with Barattieri, Cacciatore, and Ghironi (2018) who find that protectionism acts as a supply shock by decreasing output and increasing inflation in the short run. They also find that protectionism leads to higher inflation which, in turn, prompts central banks to respond with a contractionary impulse.

\section{$\underline{\text { Robustness Checks }}{ }^{17}$}

The previous sub-section analyzed the heterogeneous effects of tariffs on output and productivity. This section is complementary; it presents several robustness checks to demonstrate the generality of our results. We provide three types of checks, changing: a) our key regressor; b) our estimation technique (we are especially concerned with endogeneity); and c) our sample. This sensitivity analysis is presented in a series of fifteen IRFs, which are presented for output and productivity respectively in Figures 4 and $5 .{ }^{18}$

Consider Figure 4, which presents the robustness checks for output (Figure 5 is analogous for productivity). Our default results are presented in the top-left panel of the figure to facilitate comparison. In the two other top panels, we transform our key regressor, tariffs. In the top-middle panel, we examine whether the results hold when considering tariff changes in percentage (that is, dividing our baseline measure by the lagged level of tariff), rather than absolute terms. In the top-right panel, we substitute the lag of tariffs for its contemporaneous value. In both (and indeed all) panels, the default response and its confidence interval (taken from the top-left) is plotted; the mean response 
for the perturbation is plotted with a thick black line. If it lies within the confidence interval and is relatively close to the dashed line, we consider our results to be robust.

Clearly, the exact way we transform the tariff regressor has little effect on the results. The IRFs for our different transformations of tariffs indicate that the output response to changes in tariff are not statistically different from those reported in the baseline: in both cases, these responses lie well inside the confidence bands of the baseline responses.

\section{Estimation Sensitivity}

Our specification implicitly assumes that shocks to the tariff do not respond to changes in the outcome variables within a year. To check whether the results are sensitive to this assumption, we use three alternative estimation techniques. First, we perform a VAR analysis, using a Cholesky decomposition with the following order to recover orthogonal shocks: the change in the log of output (or productivity), the change in tariff, the change in log of real exchange rate and the change in trade balance (in percent of GDP). ${ }^{19}$ Next, we modify equation (1) by controlling for the contemporaneous changes in the trade balance and the real exchange rate-this is equivalent to considering shocks to the tariff that are orthogonal to contemporaneous shocks in these variables. ${ }^{20,21}$ Another possible concern is that countries implement tariff changes because of concerns regarding future weak economic growth. To address this issue, we estimate a specification that controls for past growth as well as for expected at $t-1$ of future GDP growth rates (using IMF WEO 
forecasts). These three perturbations are presented in the second row of Figure 4, and do not fundamentally change our conclusions.

To address the endogeneity concerns further, we implement an instrumental variable (IV) approach. As an instrument, we use the weighted-average of changes in the tariff in major (top 5) trading-partner countries, where the weights are determined by the strength of trade linkages with other countries. Specifically, the instrument is computed as follows:

$I_{i, t}=\sum_{j=1,5(j \neq i)} \Delta T_{j, t} w_{i, j, t}$

where $I_{i, t}$ is the instrument of tariff for country $i$ at time t; $\Delta T_{j, t}$ is the change in the tariff for country $j$ (up to the 5 largest trading partners) at time $t$; and $w_{i, j, t}$ is the share of total exports and imports between country $\mathrm{i}$ and country $\mathrm{j}$ in the total exports and imports for country $i: \frac{\text { Export }_{i, j, t}+\text { Import }_{i, j, t}}{\text { Export }_{i, t}+\text { Import }_{i, t}}$.

The first-stage estimates suggest that this instrument is "strong" and statistically significant (see Appendix $V$ for details). ${ }^{22}$ In addition, we consider the instrument to be plausibly exogenous, since changes in the tariff in major (top 5) trading-partner countries are unlikely to be correlated with the error term of Equation (1), once we control for lagged changes in domestic macroeconomic variables (output, real exchange rates, tariff and trade balance). We perform exclusion-restriction tests and find that tariff changes in major 
trading partners do not have any effect on output or other outcome variables of interest in country $i$ if not through tariff changes in country $i^{23}$

Our IV results are presented in the middle-left panel. The IV technique is noisier than our default technique but leads to an even larger decline in output within five years. To be conservative, we stick with our default technique. But the important message is that our results do not evaporate with different estimation techniques.

\section{Sample Sensitivity}

In our final set of aggregate results, we check the robustness of the results to a number of perturbations to the sample size. We change our sample of data in eight ways: a) we drop series with gaps and less than 20 consecutive years; b) we drop high inflation episodes (inflation above 100 percent); c) we drop small countries (with population below a million); d) we drop outliers (those observations corresponding to the residuals in the output regression in the bottom and top $1^{\text {st }}$ percentiles of the distribution $)^{24}$; e) we restrict the time sample to years after 1979; f) we drop high tariff episodes (those with tariff rates above 66 percent-corresponding to the $99^{\text {th }}$ percentile of the distribution); g) we drop observations from the Americas; and h) we drop Asian and Sub-Saharan African economies. Our results persist through all these perturbations.

We conclude that our results are reasonably robust. 


\section{$\underline{\text { Industry-level results }}$}

Our analysis thus far has shown that increases in tariffs lead, on average, to declines in output and productivity in the medium term. This section explores the role of sectoral input and output tariffs in shaping the aggregate effect of protectionism. Before turning to the estimated effects, it is useful to note the effect on aggregate value added of a tariff increase in sector $\mathrm{j}$ can be expressed (in the absence of output spillovers across sectors) as the sum of two components: the effect of the tariff increase on the value added of sector $j$ (that is, the output tariff effect); and its effect on the value added of all remaining sectors (that is, effects through the input channel):

$$
\frac{d Y_{t}}{d T_{j, t}}=\frac{d Y_{j, t}}{d T_{j, t}}+\sum_{S \neq j} \frac{d Y_{S, t}}{d T_{j, t}}
$$

The four panels of Figure 6 show the estimated dynamic responses of sectoral output (on the left) and productivity (on the right) to one-standard deviation increases in input tariffs (above, equivalent to an increase of about $0.4 \mathrm{ppt}$ ) and output tariffs (below, equivalent to a $2.0 \mathrm{ppt}$ increase). As always, we portray results for the five years following the tariff change and include 90 percent confidence intervals around the point estimate (computed using Driscoll-Kraay standard errors for the estimated coefficients).

The results in the top panels of Figure 6 suggest that an increase in the input tariff rate leads to a statistically-significant decline in sectoral output of about $6.4 \%$ five years 
after the tariff hike. It also results in a statistically significant decline in productivity (shown to the right) of about 3.9\% five years after the tariff hike, and again the effect is statistically significant.

While input tariff increases lead to declines in output and productivity, increases in output tariffs have a statistically positive impact on output, with output increasing by 3.1 percent in five years. The impact on productivity is positive but not statistically significant. ${ }^{25}$

To summarize, these results suggest that the negative macroeconomic effect of tariff increases presented in the previous section stems largely from increases in input tariffs.

\section{CONCLUSION}

A specter is haunting the international economy: the specter of a trade war. Well, the specter of a trade war is at least haunting economists. It is striking that the distaste for protectionism felt by the discipline is not shared by the wider public. Modern economics began over two hundred years ago in part as an intellectual exercise against mercantilism, so it is worrying that the profession has been unable to persuade the public of the merits of free trade. But perhaps some of the public's mild views on protectionism stem from the fact that most economic analysis of protectionism is theoretical, microeconomic, or dated? In this paper, we examine the macroeconomic consequence of tariffs. We use impulse response functions from local projections on a panel of annual data spanning 151 
countries over 1963-2014. The main analysis on aggregate data is complemented with industry-level data.

Our results suggest that tariff increases have an adverse impact on output and productivity; these effects are economically and statistically significant. They are magnified when tariffs are used during expansions, for advanced economies, and when tariffs go up. We also find that that tariff increases lead to more unemployment and higher inequality, further adding to the deadweight losses of tariffs. Tariffs have only small effects on the trade balance though, in part because they induce offsetting exchange rate appreciations. Finally, protectionism also leads to a decline in consumption; this, together with our other findings, suggests that tariffs are bad for welfare.

All this seems eminently sensible and bolsters the arguments that mainstream economists make against tariffs; our results can be regarded as strong empirical evidence for the benefits of liberal trade. And given the current global context, we take special note of the negative consequences when advanced economies increase tariffs during cyclical upturns.

Finally, the limitations in our approach should be borne in mind when interpreting our estimates. Though our data set contains a fair number of tariff increases, it is drawn from the postwar period which is mostly characterized by trade liberalization. While we use an instrumental variable approach to address endogeneity, it is difficult to mitigate such concerns completely. At the same, the host of robustness checks and the industry-level analysis should provide some comfort, particularly for output and productivity. 


\section{References}

Ahn, Jaebin, Era Dabla-Norris, Romain Duval, Binjie Hu, and Lamin Njie, 2016, "Reassessing the Productivity Gains from Trade Liberalization," IMF Working Paper, WP/16/77.

Alcala, F., and A. Ciccone, 2004, "Trade and Productivity," The Quarterly Journal of Economics, vol. 119(2), pp. 613-646.

Amiti, Mary, and Jozef Konings, 2007, "Trade Liberalization, Intermediate Inputs, and Productivity: Evidence from Indonesia," American Economic Review, vol. 97(5), pp. 16111638.

Artuç, E., and McLaren, J. 2015. "Trade Policy and Wage Inequality: A Structural Analysis with Occupational and Sectoral Mobility," Journal of International Economics, vol. 97(2), pp. 278-294.

Auerbach, Alan J., and Yuriy Gorodnichenko, 2012, "Measuring the Output Responses to Fiscal Policy," American Economic Journal, vol. 4(2), pp. 1-27.

Auerbach, Alan J., and Yuriy Gorodnichenko, 2013, "Output Spillovers from Fiscal Policy," American Economic Review: Papers and Proceedings, vol. 103(3), pp. 141-146.

Barattieri, Alessandro, Matteo Cacciatore, and Fabio Ghironi, 2018, "Protectionism and the Business Cycle," NBER Working Paper No. 24353.

Bonadio, Barthelemy, and Andrei A. Levchenko, 2018, "The economics and politics of revoking NAFTA," mimeo, https://www.imf.org/en/News/Seminars/Conferences/2018/02/08/ /media/D161FF9ABB1 741C6874C8A8E4F938762.ashx.

Corcose, G., M. del Gatto, G. Mion, and G. Ottaviano, 2012, “Productivity and Firm Selection: Quantifying the New Gains from Trade," Economic Journal, vol. 122, pp. 754-798.

Dornbusch, Rudiger, 1974, "Tariffs and Nontraded Goods," Journal of International Economics, vol. 4(2), pp. 177-85.

Edwards, Sebastian, 1989, Real Exchange Rates, Devaluation, and Adjustment (Cambridge, Massachusetts: MIT Press).

Feyrer, J., 2009, “Distance, Trade, and Income - The 1967 to 1975 Closing of the Suez Canal as a Natural Experiment," NBER Working Paper No. 15557.

Granger, Clive W. J., and Timo Terasvirta, 1993, Modelling Nonlinear Economic Relationships (New York: Oxford University Press).

Grossman, Gene M., and Kenneth Rogoff, 1995, Handbook of International Economics, Volume III (Amsterdam: Elsevier Science Publishers B.V.).

Helpman, E., 2016, “Globalization and Wage Inequality,” NBER Working Paper No. 22944. 
Irwin, Douglas A., 2014, “Tariff Incidence: Evidence from U.S. Sugar Duties, 1890-1930," NBER Working Paper No. 20635.

Jaumotte, F., Lall, S., Papageorgiou, C., 2013. "Rising income inequality: technology, or trade and financial globalization?" IMF Economic Review, 61, 271-309.

Jordà, Oscar, 2005, "Estimation and Inference of Impulse Responses by Local Projections," American Economic Review, vol. 95(1), pp. 161-182.

Ju, Jiandong, Yi Wu and Li Zeng, 2010, "The Impact of Trade Liberalization on the Trade Balance in Developing Countries," IMF Staff Papers, vol. 57(2), pp. 427-449.

Kehoe, T.J., 2003, "An Evaluation of the Performance of Applied General Equilibrium Models of the Impact of NAFTA", Staff Report 320, Federal Reserve Bank of Minneapolis.

Klein, M. W., Moser, C., and Urban, D. M., 2010. "The Contribution of Trade to Wage Inequality: The Role of Skill, Gender, and Nationality," NBER Working Paper 15985.

Leibovici, Fernando, and Jones Crews, 2018, "Trade Liberalization and Economic Development," Economic Synopses, No. 13, Economic Research, Federal Reserve Bank of St. Louis. https://research.stlouisfed.org/publications/economic-synopses/2018/04/20/tradeliberalization-and-economic-development.

Li, Xiangming, 2004, "Trade Liberalization and Real Exchange Rate Movement," IMF Staff Papers, vol. 51(3), pp. 553-584.

Ostry, Jonathan D., and Andrew K. Rose, 1992, "An Empirical Evaluation of the Macroeconomic Effects of Tariffs," Journal of International Money and Finance, vol. 11, pp. 63-79.

Rose, Andrew K., 2013, "Protectionism isn't Counter-Cyclic (anymore)," Economic Policy, vol. 28(76), pp. 569-612.

Santos-Paulino, Amelia U., and A.P. Thirlwall, 2004, "The Impact of Trade Liberalisation on Exports, Imports, and the Balance of Payments of Developing Countries," Economic Journal, vol. 114, pp. 50-72.

Stock, James, and Mark Watson, "Why Has U.S. Inflation Become Harder to Forecast?" Journal of Money, Banking and Credit, vol. 39(1), pp. 3-33.

Topalova, Petia, and Amit Khandelwal, 2011, "Trade Liberalization and Firm Productivity: The Case of India," The Review of Economics and Statistics, vol. 93(3), pp. 995-1009.

UNCTAD, 1999, Trade and Development Report (Geneva, UNCTAD). 
Table 1. Data Sources for Country-level Analysis

\begin{tabular}{|l|l|}
\hline Indicator & Source \\
\hline Total employment (persons, millions) & World Economic Outlook (WEO) \\
Unemployment rate (percent) & WEO and World Development Indicators from World Bank (WDI) \\
$\begin{array}{l}\text { Gross Domestic Product in constant prices (national currency, } \\
\text { billions) }\end{array}$ & WEO and WDI \\
$\begin{array}{l}\text { Growth of Real GDP Exp. In Current Oct. Pub. (\%) } \\
\text { Real effective exchange rate (2010=100) }\end{array}$ & WEO \\
Gini net mean of 100 & Information Notice System (IMF) \\
Tariff rates & $\begin{array}{l}\text { The Standardized World Income Inequality Database (SWIID) } \\
\text { Sructural Reform database, IMF (forthcoming). Main sources are the WITS, WDI, WTO, GATT, BTN (Brussels } \\
\text { Trade balance as a share of GDP; Trade balance is computed using } \\
\text { exports of goods and services, and imports of goods and services. } \\
\text { Exports, imports and GDP are in constant prices (national currency, } \\
\text { billions) }\end{array}$ \\
Instruments for tariff & WEO and WDI \\
\hline
\end{tabular}

Table 2. List of Countries in Country-level Analysis

\begin{tabular}{|c|c|c|c|c|}
\hline Albania & China & Hungary & Moldova & Singapore \\
\hline Algeria & Colombia & Iceland & Mongolia & Slovak Republic \\
\hline Angola & Comoros & India & Montenegro, Rep. of & Slovenia \\
\hline Antigua and Barbuda & Congo, Republic of & Indonesia & Morocco & South Africa \\
\hline Argentina & Costa Rica & Iran & Mozambique & Spain \\
\hline Armenia & Croatia & Ireland & Myanmar & Sri Lanka \\
\hline Australia & Cyprus & Israel & Namibia & St. Lucia \\
\hline Austria & Czech Republic & Italy & Nepal & Swaziland \\
\hline Azerbaijan & Cote d'Ivoire & Jamaica & Netherlands & Sweden \\
\hline Bahrain & Denmark & Japan & New Zealand & Taiwan Province of China \\
\hline Bangladesh & Dominica & Jordan & Nicaragua & Tanzania \\
\hline Barbados & Dominican Republic & Kazakhstan & Niger & Thailand \\
\hline Belarus & Ecuador & Kenya & Nigeria & Togo \\
\hline Belgium & Egypt & Korea & Norway & Tonga \\
\hline Belize & El Salvador & Kuwait & Oman & Trinidad and Tobago \\
\hline Benin & Estonia & Kyrgyz Republic & Pakistan & Tunisia \\
\hline Bolivia & Ethiopia & Lao P.D.R. & Panama & Turkey \\
\hline Bosnia and Herzegovina & Finland & Latvia & Papua New Guinea & Turkmenistan \\
\hline Botswana & France & Lebanon & Paraguay & Uganda \\
\hline Brazil & Gabon & Lithuania & Peru & Ukraine \\
\hline Brunei Darussalam & Gambia, The & Luxembourg & Philippines & United Arab Emirates \\
\hline Bulgaria & Germany & Macedonia, FYR & Poland & United Kingdom \\
\hline Burkina Faso & Ghana & Madagascar & Portugal & United States \\
\hline Burundi & Greece & Malawi & Qatar & Uruguay \\
\hline Cabo Verde & Guatemala & Malaysia & Romania & Uzbekistan \\
\hline Cambodia & Guinea & Mali & Russia & Vanuatu \\
\hline Cameroon & Guinea-Bissau & Malta & Rwanda & Venezuela \\
\hline Canada & Haiti & Mauritania & Saudi Arabia & Vietnam \\
\hline Central African Republic & Honduras & Mauritius & Senegal & Yemen \\
\hline Chad & Hong Kong SAR & Mexico & Sierra Leone & Zambia \\
\hline Chile & & & & \\
\hline
\end{tabular}


Table 3. List of Countries in Industry-level Analysis

\begin{tabular}{|l|l|}
\hline United States & South Africa \\
United Kingdom & Cyprus \\
Austria & Indonesia \\
Belgium & Korea \\
Denmark & Philippines \\
France & Vietnam \\
Germany & Morocco \\
Italy & Bulgaria \\
Luxembourg & Russia \\
Netherlands & China \\
Sweden & Czech Republic \\
Canada & Slovak Republic \\
Finland & Estonia \\
Greece & Latvia \\
Ireland & Hungary \\
Malta & Lithuania \\
Portugal & Slovenia \\
Spain & Poland \\
Australia & Romania \\
New Zealand & \\
\hline
\end{tabular}

\section{Table 4. List of Industries}

Food products, beverages and tobacco

Textiles, textile products, leather and footwear

Wood and products of wood and cork

Pulp, paper, paper products, printing and publishing

Coke, refined petroleum products and nuclear fuel

Chemicals and chemical products

Rubber and plastics products

Other non-metallic mineral products

Basic metals

Fabricated metal products

Machinery and equipment, nec

Computer, Electronic and optical equipment

Electrical machinery and apparatus, nec

Motor vehicles, trailers and semi-trailers

Other transport equipment

Manufacturing nec; recycling 
Table 5. List of Advanced Economies in Country-level Analysis

\begin{tabular}{|l|l|}
\hline Australia & Japan \\
Austria & Korea \\
Belgium & Latvia \\
Canada & Luxembourg \\
Cyprus & Malta \\
Czech Republic & Netherlands \\
Denmark & New Zealand \\
Estonia & Norway \\
Finland & Portugal \\
France & Singapore \\
Germany & Slovak Republic \\
Greece & Slovenia \\
Hong Kong SAR & Spain \\
Iceland & Sweden \\
Ireland & Taiwan Province of China \\
Israel & United Kingdom \\
Italy & United States \\
\hline
\end{tabular}


Table 6. The Aggregate and Distributional Effects of Tariffs 1/

\begin{tabular}{|c|c|c|c|c|c|c|}
\hline & A & B & C & D & $E$ & $F$ \\
\hline & $\begin{array}{c}\text { Output } \\
\text { (\%) }\end{array}$ & $\begin{array}{c}\text { Real exchange } \\
\text { rate (\%) }\end{array}$ & $\begin{array}{c}\text { Trade balance } \\
\text { (ppt) }\end{array}$ & $\begin{array}{c}\text { Productivity } \\
\text { (\%) }\end{array}$ & $\begin{array}{l}\text { Unemployment } \\
\text { (ppt) }\end{array}$ & $\begin{array}{c}\text { Inequality } \\
\text { (ppt) }\end{array}$ \\
\hline$t=0$ & $\begin{array}{c}0.013 \\
(-0.026)\end{array}$ & $\begin{array}{l}0.196 * * \\
(-0.076)\end{array}$ & $\begin{array}{l}-0.02657 \\
(0.01759)\end{array}$ & $\begin{array}{c}0.015 \\
(-0.037)\end{array}$ & $\begin{array}{l}-0.02384 \\
(0.01578)\end{array}$ & $\begin{array}{c}0.00308 \\
(0.00460)\end{array}$ \\
\hline$t=1$ & $\begin{array}{l}-0.008 \\
(-0.035)\end{array}$ & $\begin{array}{c}0.161 \\
(-0.099)\end{array}$ & $\begin{array}{l}-0.00964 \\
(0.03011)\end{array}$ & $\begin{array}{l}-0.040 \\
(-0.048)\end{array}$ & $\begin{array}{c}0.00707 \\
(0.01496)\end{array}$ & $\begin{array}{c}0.01498 \\
(0.01017)\end{array}$ \\
\hline$t=2$ & $\begin{array}{c}-0.063 \\
(-0.045)\end{array}$ & $\begin{array}{c}0.075 \\
(-0.103)\end{array}$ & $\begin{array}{l}-0.00492 \\
(0.03135)\end{array}$ & $\begin{array}{c}-0.107 * * \\
(-0.049)\end{array}$ & $\begin{array}{c}0.03176 \\
(0.02646)\end{array}$ & $\begin{array}{l}0.02332^{*} \\
(0.01344)\end{array}$ \\
\hline$t=3$ & $\begin{array}{c}-0.066 \\
(-0.052)\end{array}$ & $\begin{array}{c}0.083 \\
(-0.111)\end{array}$ & $\begin{array}{c}0.01719 \\
(0.03704)\end{array}$ & $\begin{array}{c}-0.150 * * * \\
(-0.044)\end{array}$ & $\begin{array}{c}0.04171 \\
(0.03187)\end{array}$ & $\begin{array}{c}0.03732 * * \\
(0.01756)\end{array}$ \\
\hline$t=4$ & $\begin{array}{l}-0.111^{*} \\
(-0.059)\end{array}$ & $\begin{array}{c}0.092 \\
(-0.128)\end{array}$ & $\begin{array}{c}0.01488 \\
(0.04820)\end{array}$ & $\begin{array}{c}-0.177^{* * *} \\
(-0.055)\end{array}$ & $\begin{array}{c}0.02708 \\
(0.02963)\end{array}$ & $\begin{array}{c}0.03380 \\
(0.02017)\end{array}$ \\
\hline$t=5$ & $\begin{array}{l}-0.119^{*} \\
(-0.063)\end{array}$ & $\begin{array}{c}0.180 \\
(-0.139)\end{array}$ & $\begin{array}{l}-0.00042 \\
(0.04308)\end{array}$ & $\begin{array}{c}-0.234^{* * *} \\
(-0.068)\end{array}$ & $\begin{array}{c}0.04248 \\
(0.03035)\end{array}$ & $\begin{array}{l}0.04030 * \\
(0.02311)\end{array}$ \\
\hline $\begin{array}{c}\text { Average number of } \\
\text { observations } \\
\text { Average number of } \\
\text { countries }\end{array}$ & 3468 & 3354 & 3466 & 2217 & 1350 & 2331 \\
\hline
\end{tabular}

The table reports the response of outcome variables to 1 percentage point increase in tariffs $t$ years after the tariff increase. For example, the data point for column $\mathrm{A}$ at $t=5$ denotes that, following a 1 percentage point increase in tariffs, output declines by 0.119 percent five years after the tariff increase.

Note: Standard errors are reported in parenthesis. ${ }^{* * *}, * *$, and * denote significance at 1 percent, 5 percent, and 10 percent, respectively. Estimates based on equation (1). 
Panel A. Output (\%)

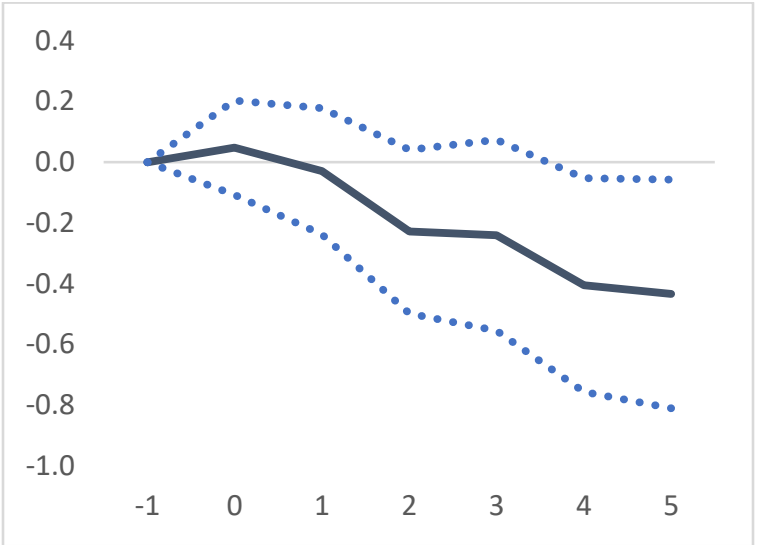

Panel C. Unemployment (ppt)

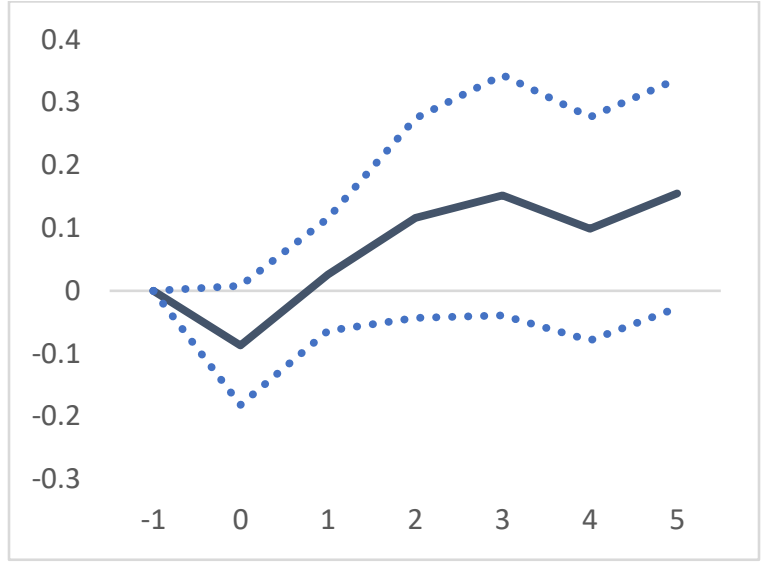

\section{Panel E. Real exchange rate (\%)}

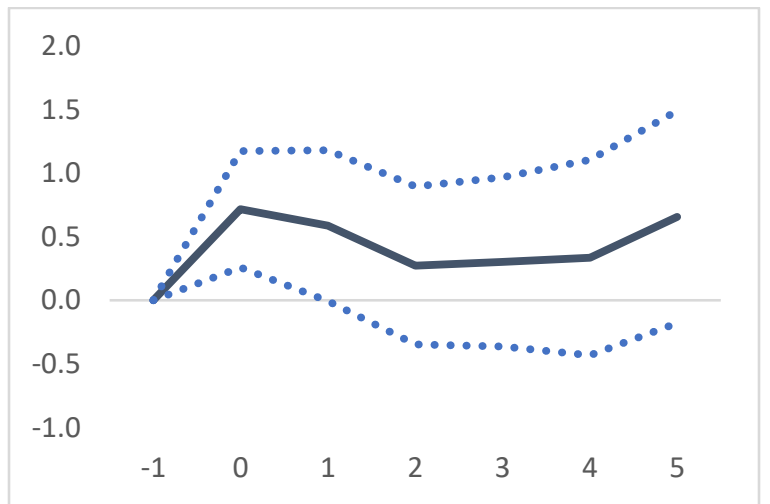

Panel B. Productivity (\%)

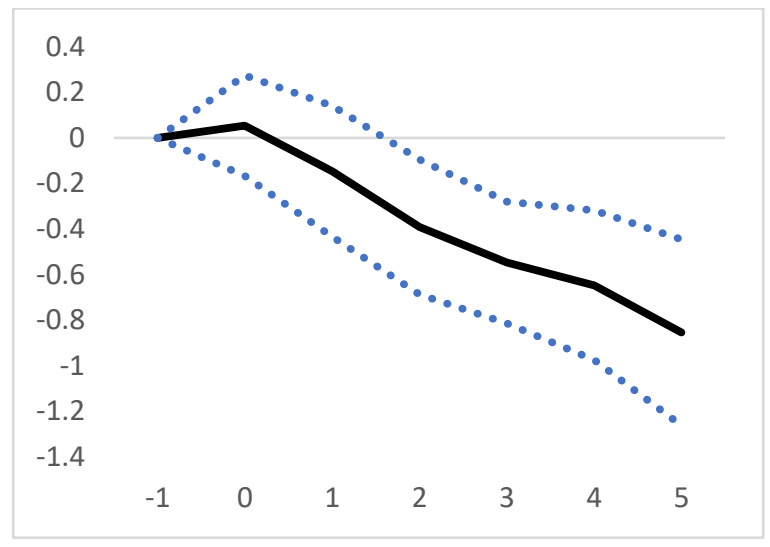

\section{Panel D. Inequality (ppt)}

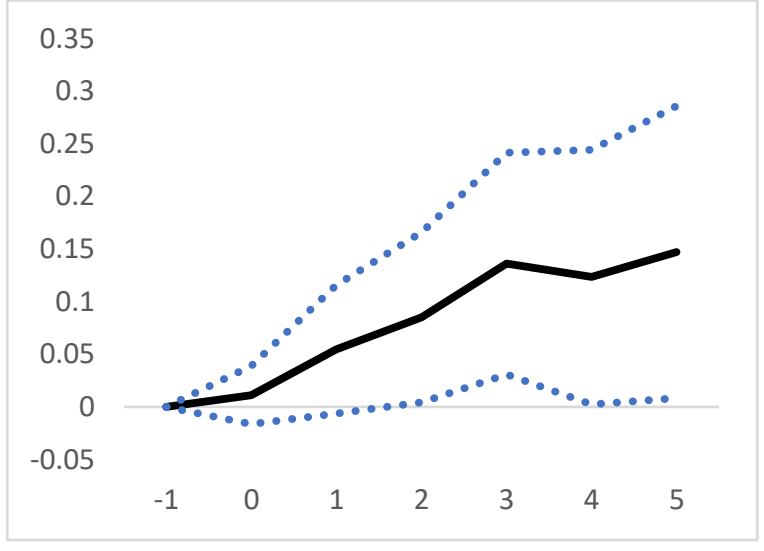

Panel F. Trade balance-to-GDP ratio (ppt)

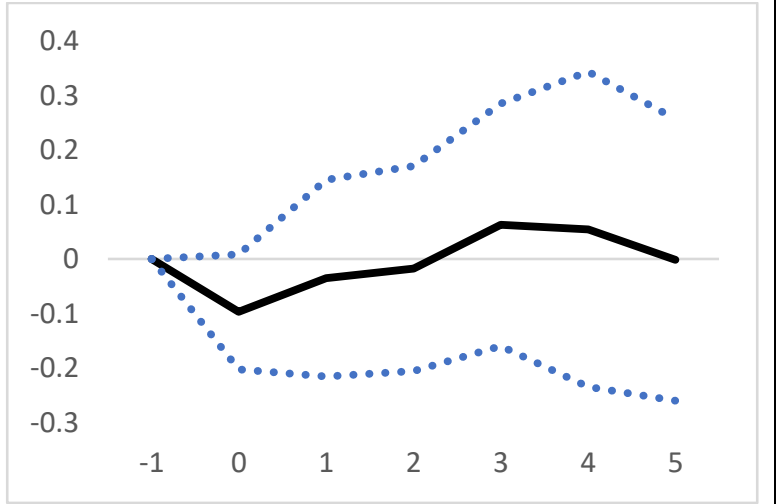

Note: The solid line indicates the response of output (real exchange rate, trade balance, labor productivity, unemployment, inequality) to a one standard deviation increase in tariff; the dotted lines correspond to $90 \%$ confidence bands. The $x$-axis denotes time. $t=0$ is the year of the change. The estimates are based on equation (1). 


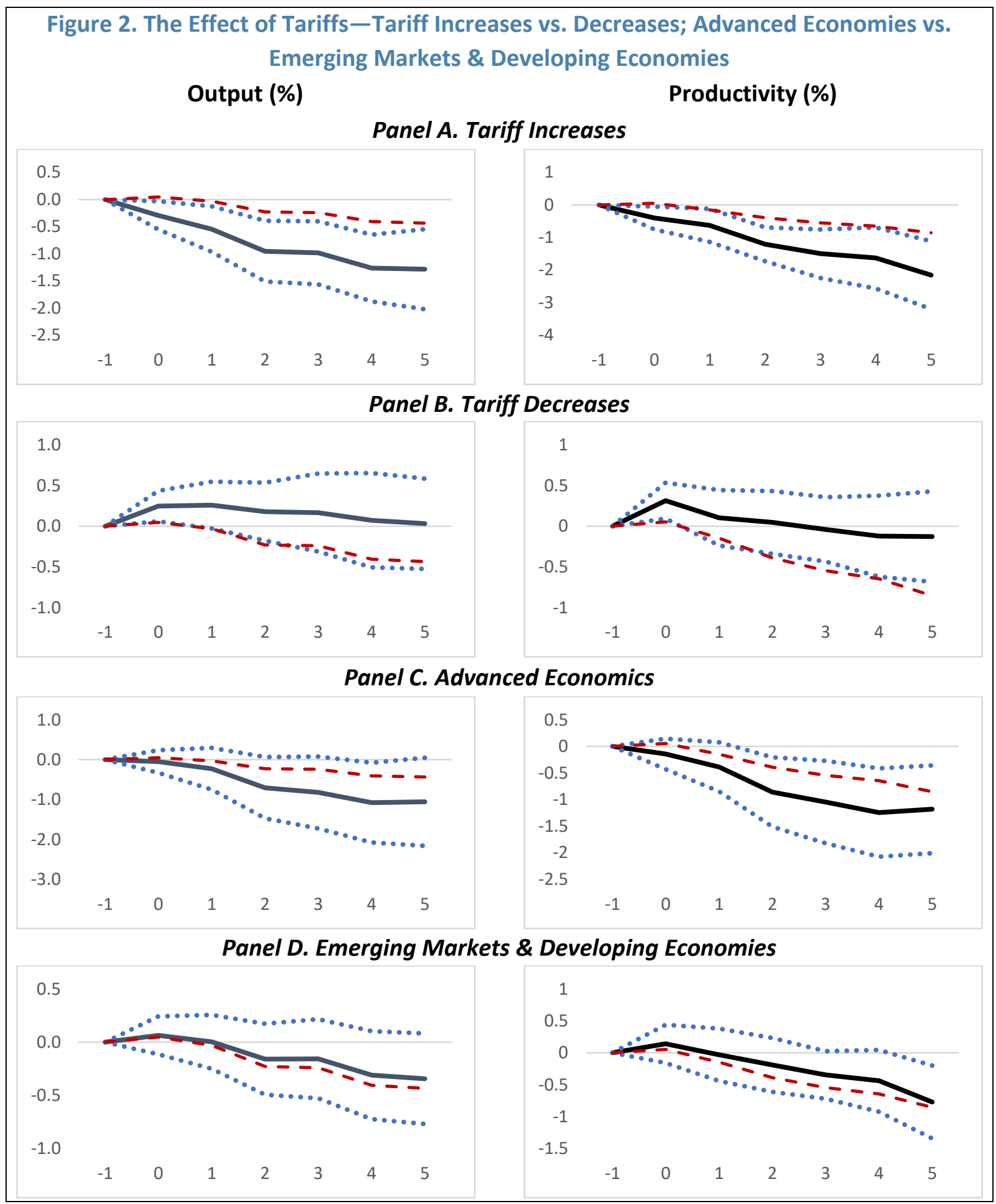

Note: The solid black line indicates the response of output (productivity) to a one standard deviation increase and decrease in tariff (advanced economies and emerging markets \& developing economies); the dotted lines correspond to $90 \%$ confidence bands; estimates for Panel A and B are based on equation (2); estimates for Panel C and D are based on equation (3). Dashed red lines indicate the response of output (productivity) to a one standard deviation increase in tariff in the baseline; estimates based on equation (1). The $x$-axis denotes time. $t=0$ is the year of the tariff change. 


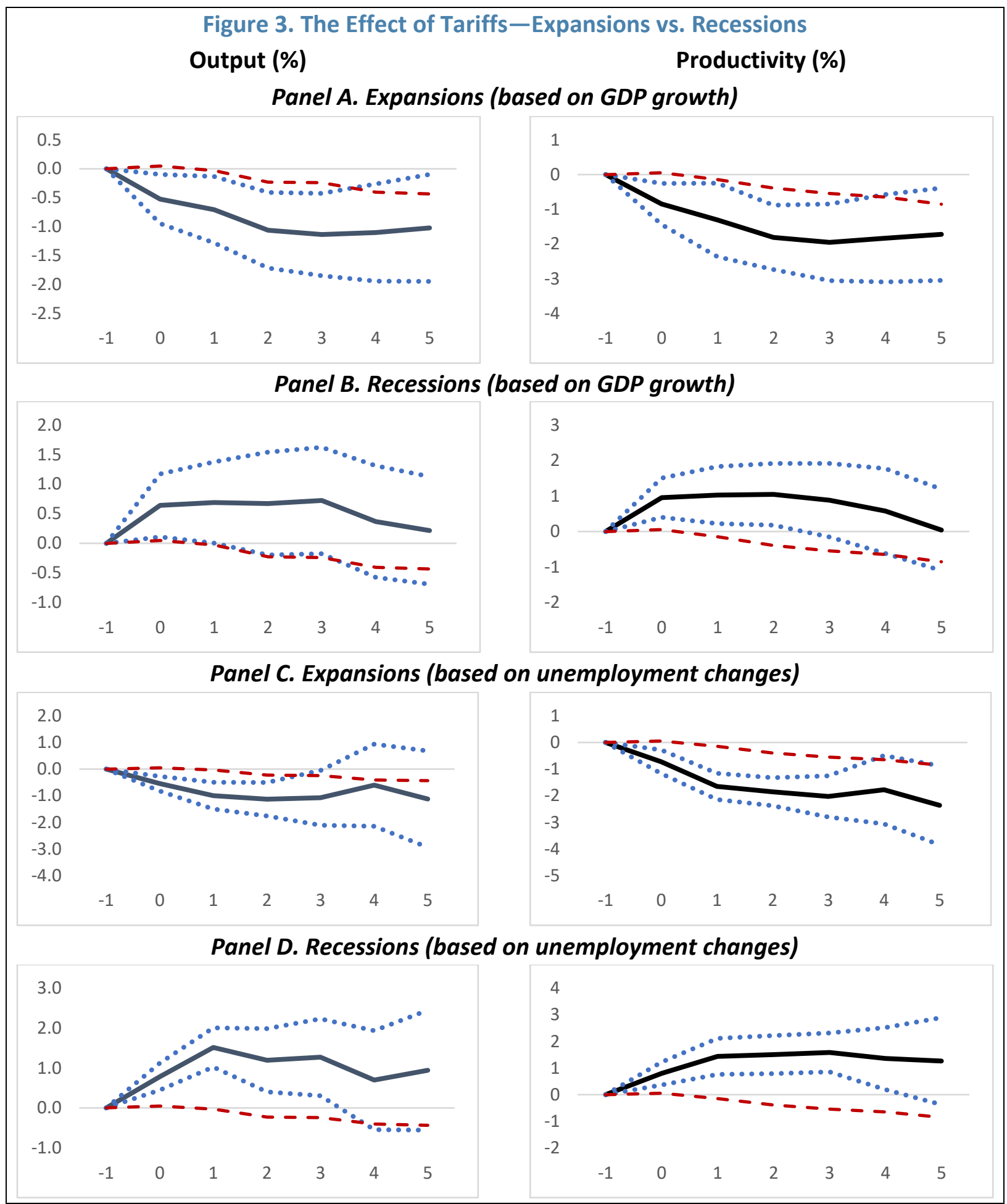

Note: The solid black line indicates the response of output (productivity) to a one standard deviation increase in tariff during expansions and recessions; the dotted lines correspond to $90 \%$ confidence bands; estimates based on equation (4); for Panel A and B expansions and recessions are identified using GDP growth; for Panel $C$ and $D$ using unemployment changes. Dashed red lines indicate the response of output (productivity) to a one standard deviation increase in tariff in the baseline; estimates based on equation (1). The $x$-axis denotes time. $t=0$ is the year of the tariff change. 
Figure 4. Robustness for Output
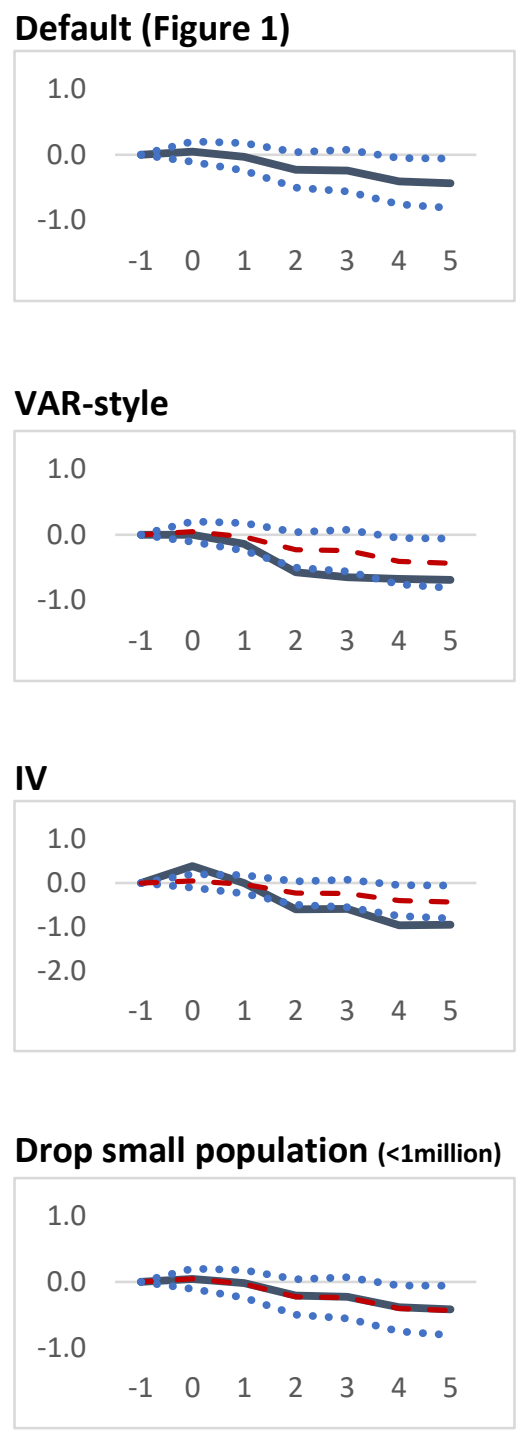

Drop high tariffs (>66 percent)

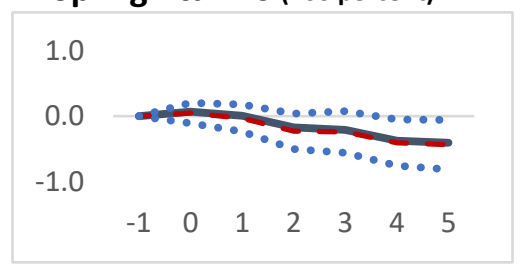

\section{Percent change of tariffs}

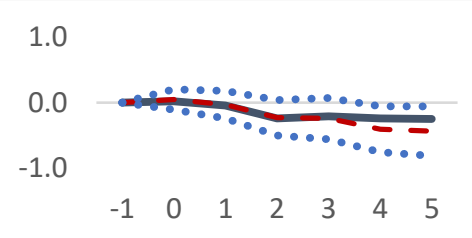

Include contemporary shocks

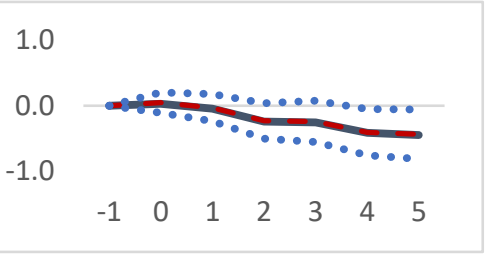

Drop series with gaps

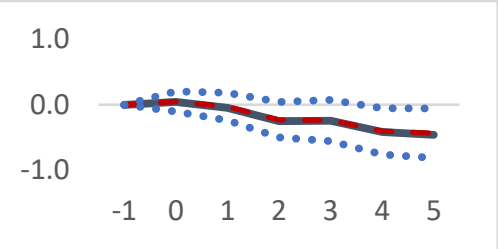

\section{Drop outliers}

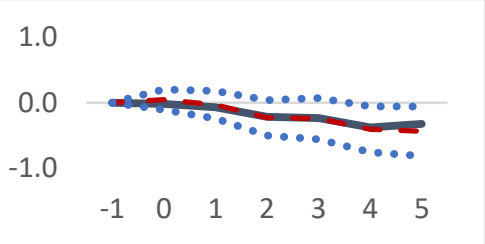

Drop Americas

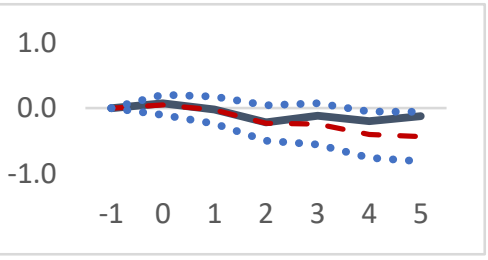

Lag tariffs

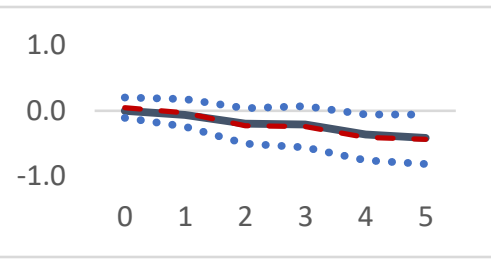

Include growth forecasts

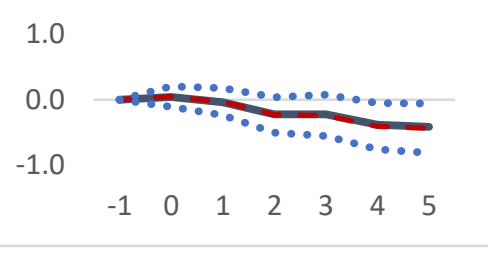

Drop high inflation $(>100 \%)$

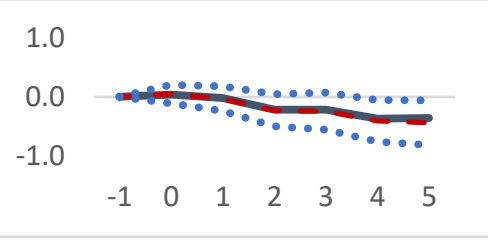

Drop early years $(<1980)$

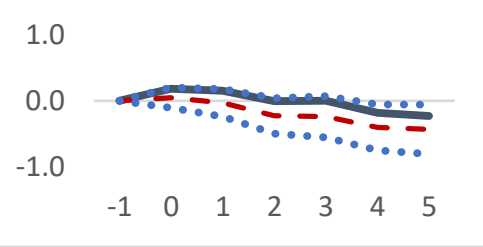

\section{Drop Asians/Africans}

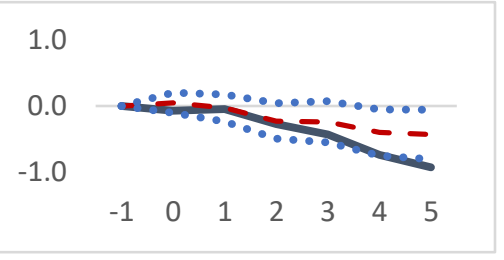

Note: The black solid line indicates the response of output to a one standard deviation increase in tariff using the scenarios described in each title of the chart. The red dotted line represents the baseline results, estimated based on equation (1). The blue dotted lines correspond to $90 \%$ confidence bands of the baseline. The $\mathrm{x}$-axis denotes time. $\mathrm{t}=0$ is the year of the change. 
Figure 5. Robustness for Productivity
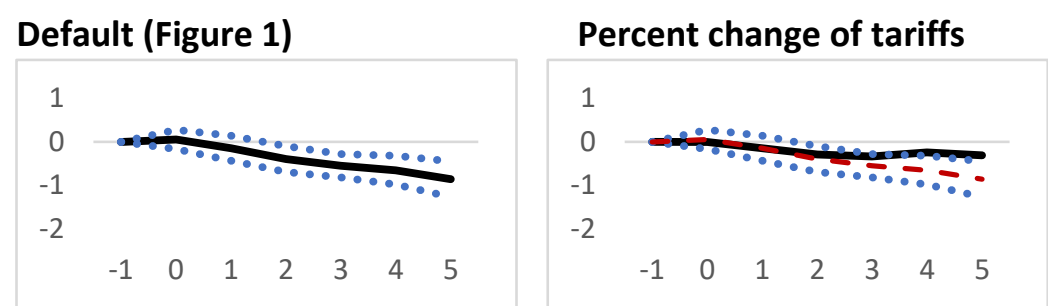

Lag tariffs
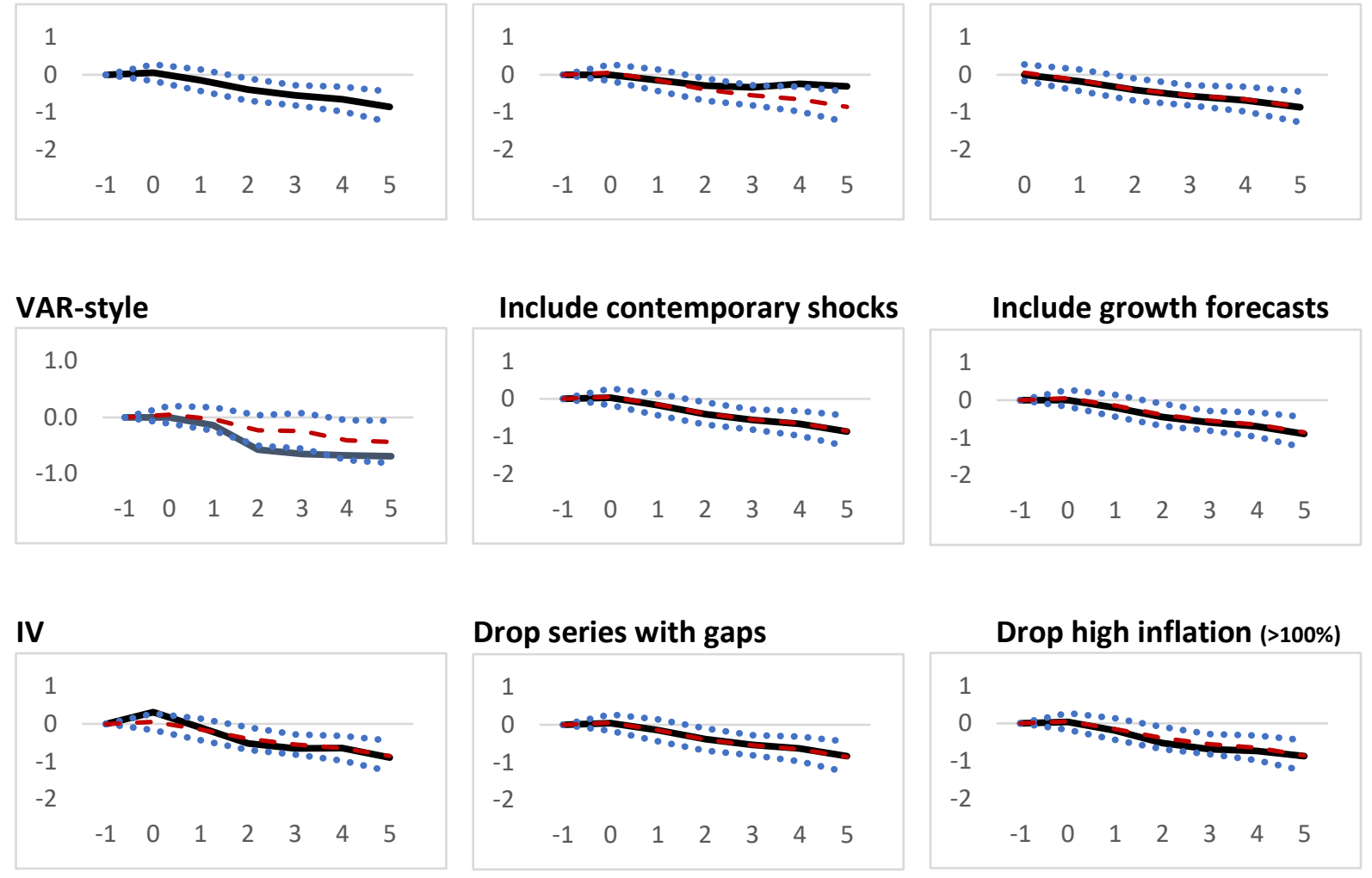

Include growth forecasts

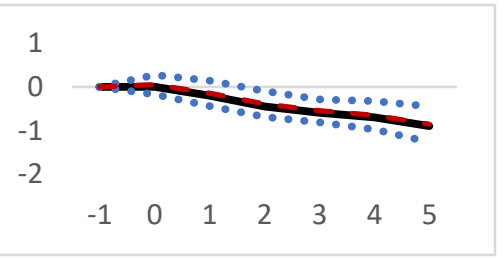

Drop small population (<1million)

Drop outliers

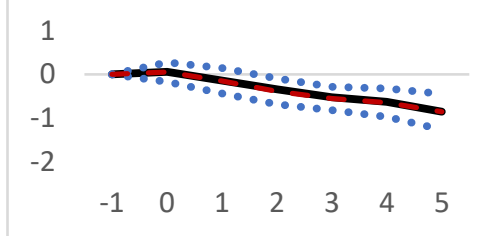

Drop high tariffs (>66 percent)

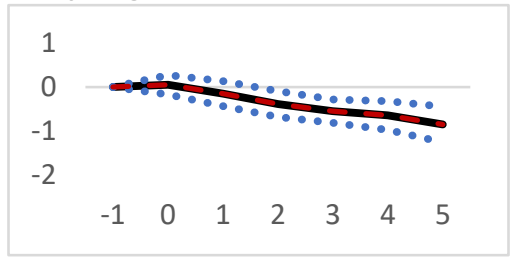

Drop Americas

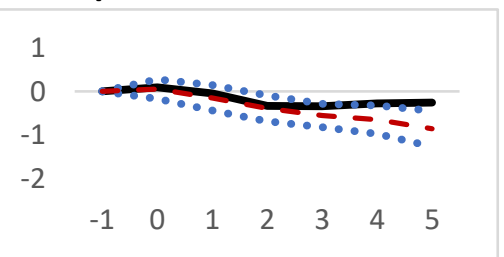

Drop high inflation (>100\%)

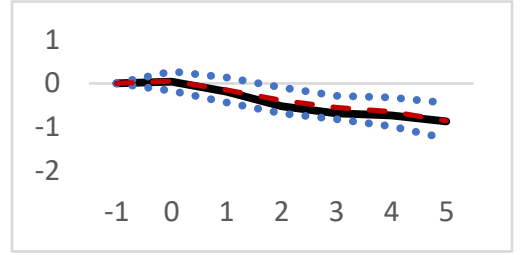

\section{Drop early years $(<1980)$}

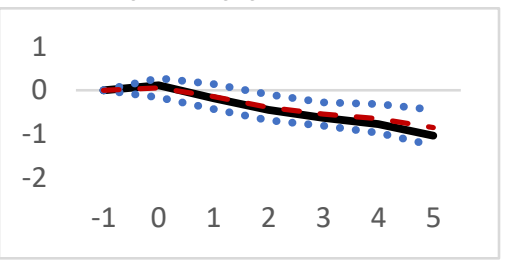

Drop Asians/Africans

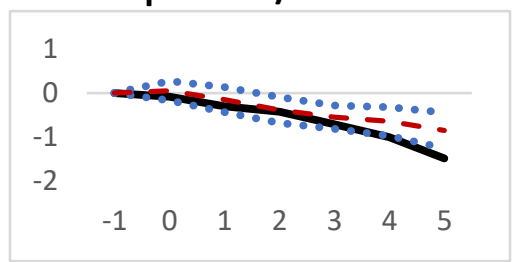

Note: The black solid line indicates the response of productivity to a one standard deviation increase in tariff using the scenarios described in each title of the chart. The red dotted line represents the baseline results, estimated based on equation (1). The blue dotted lines correspond to $90 \%$ confidence bands of the baseline. The $x$-axis denotes time. $t=0$ is the year of the change. 
Figure 6. The Effect of Tariffs using Industry-level Data

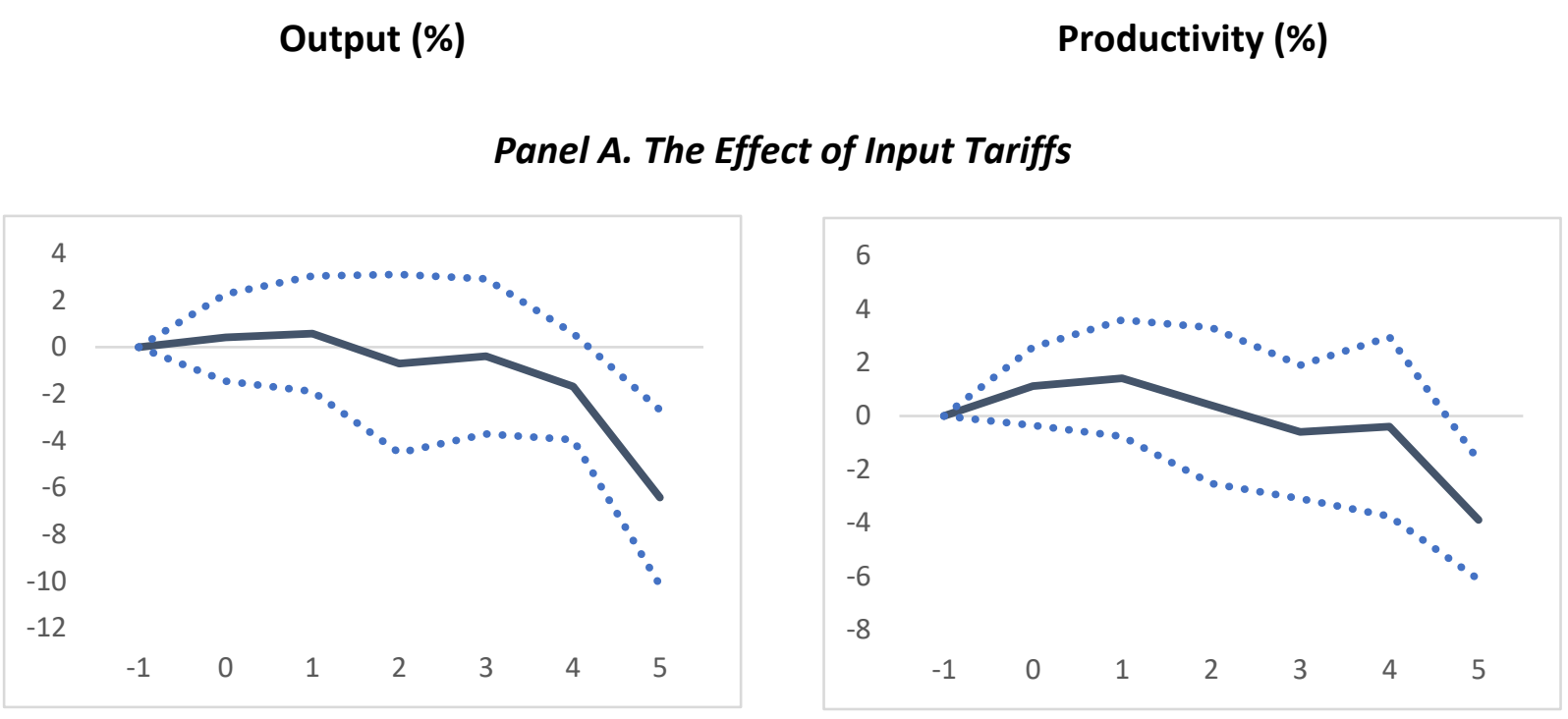

\section{Panel B. The Effect of Output Tariffs}
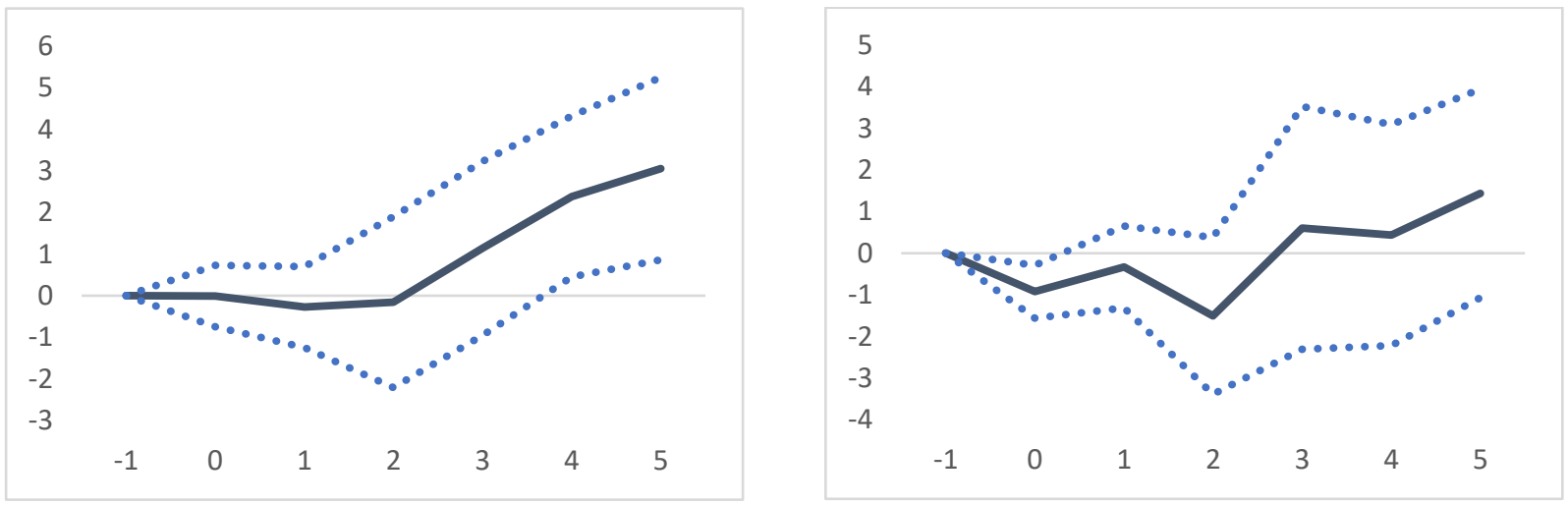

Note: The solid line indicates the response of output/labor productivity to a one standard deviation increase in input/output tariff; the dotted lines correspond to $90 \%$ confidence bands. The $x$-axis denotes time. $t=0$ is the year of the change. The estimates are based on equation ( $\left.1^{\prime}\right)$. 


\section{Appendix I-Three Episodes of Tariff Hikes}

In this appendix, we briefly describe three cases where tariffs rose in our sample. Without claiming these episodes represent all tariff variation, they seem typical to us. Tariffs rose in Denmark mostly because of a foreign shock, in Colombia because of overshooting in the foreign exchange market, and in India because of a war. In no case do domestic macroeconomic considerations seem to be overwhelming; in all cases, the primary causes seem wrapped up in the balance of payments.

\section{Denmark 1971}

Most advanced economies have tariffs that start relatively low and fall throughout most of the sample period. But there are some exceptions. Denmark's newly elected Social Democratic government moved to impose a ten percent import surcharge on two-thirds of the country's imports on its first day in office, Oct 19, 1971. ${ }^{*}$ It was introduced to strengthen the currency and improve the balance of payments before the country joined the European Economic Community (the predecessor to the European Union) and was explicitly limited in duration. This surcharge was a partial response to the "Nixon Shock" of August 1971, which imposed a ten percent surcharge on all dutiable American imports, intended to force a real American depreciation. ${ }^{\dagger}$ In our data set, the jump in Danish tariffs shows up clearly:

\begin{tabular}{|c|c|}
\multicolumn{1}{c}{ Year } & Tariff \\
\hline 1971 & $7.3 \%$ \\
\hline 1972 & $12.0 \%$ \\
\hline 1973 & $12.8 \%$ \\
\hline 1974 & $11.0 \%$ \\
\hline
\end{tabular}

\section{Colombia 1964}

A number of developing countries experienced extreme protectionism, especially countries pursuing import-substitution strategies. But there are other causes; some of the protectionist surges were triggered by balance of payments issues. In late 1964, the central bank of Colombia floated the over-valued exchange rate, which then depreciated excessively, by almost $90 \%$. Colombia then moved to protect its international reserves by

\footnotetext{
${ }^{*}$ https://www.nytimes.com/1971/10/20/archives/denmark-moved-quickly-on-surtax.html

${ }^{\dagger}$ https://www.nytimes.com/1971/10/20/archives/denmark-plans-surcharge-as-protectionist-measure-europeantrading.html
} 
prohibiting the free import of almost all foreign products for a 90-day period, pursued a standby package with the IMF, and ... raised tariffs. ${ }^{\ddagger}$

\begin{tabular}{|c|c|}
\multicolumn{1}{c}{ Year } & \multicolumn{1}{c|}{ Tariff } \\
\hline 1961 & $31.5 \%$ \\
\hline 1962 & $49.8 \%$ \\
\hline 1963 & $47.3 \%$ \\
\hline 1964 & $70.4 \%$ \\
\hline 1965 & $55.3 \%$ \\
\hline 1966 & $36.1 \%$ \\
\hline
\end{tabular}

India 1972

Indian development post-independence was guided by a series of five-year plans. By the fourth plan (covering 1969-73), there was a deliberate attempt to steer the economy towards self-reliance through import-substitution. ${ }^{\S}$ As part of the plan, tariffs were imposed on all goods other than grain and a few smaller exceptions. Still, the more immediate reason for the protectionist spike was undoubtedly the Indo-Pakistani war of December 1971.

\begin{tabular}{|l|l|}
\hline 1969 & $59.4 \%$ \\
\hline 1970 & $58.7 \%$ \\
\hline 1971 & $63.8 \%$ \\
\hline 1972 & $91.4 \%$ \\
\hline 1973 & $76.2 \%$ \\
\hline 1974 & $64.9 \%$ \\
\hline
\end{tabular}

${ }^{\ddagger}$ https://www.nytimes.com/1964/12/02/archives/colombia-curbs-all-free-imports-90day-ban-is-imposedlatinbloc.html; also see "The Political Economy of Exchange Rate Policy in Colombia" by Jaramillo, Steiner and Salazar, IDB Working Paper No. 102, 1999.

${ }^{\S}$ http://shodhganga.inflibnet.ac.in/bitstream/10603/32033/14/14_chapter\%208.pdf 


\section{APPENDIX II-RESULTS FOR UNEMPLOYMENT, INEQUALITY, REAL EXCHANGE RATE, AND TRADE BALANCE}

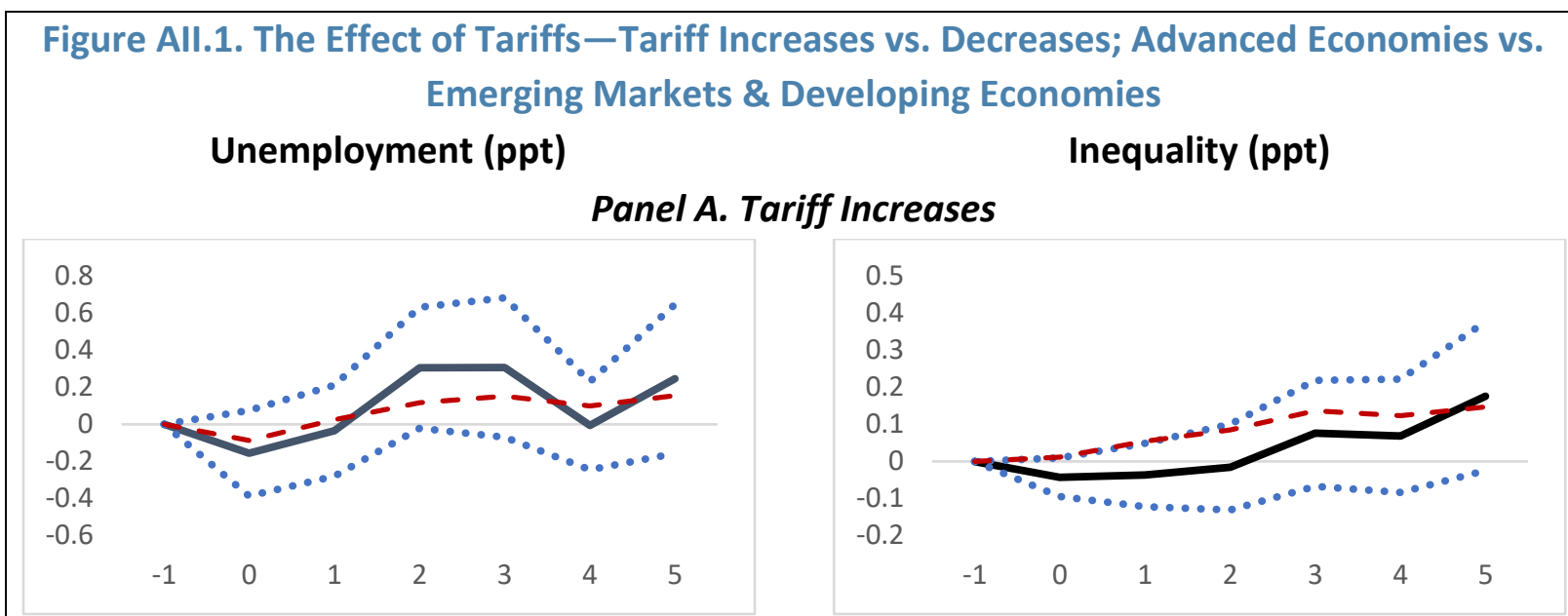

Panel B. Tariff Decreases

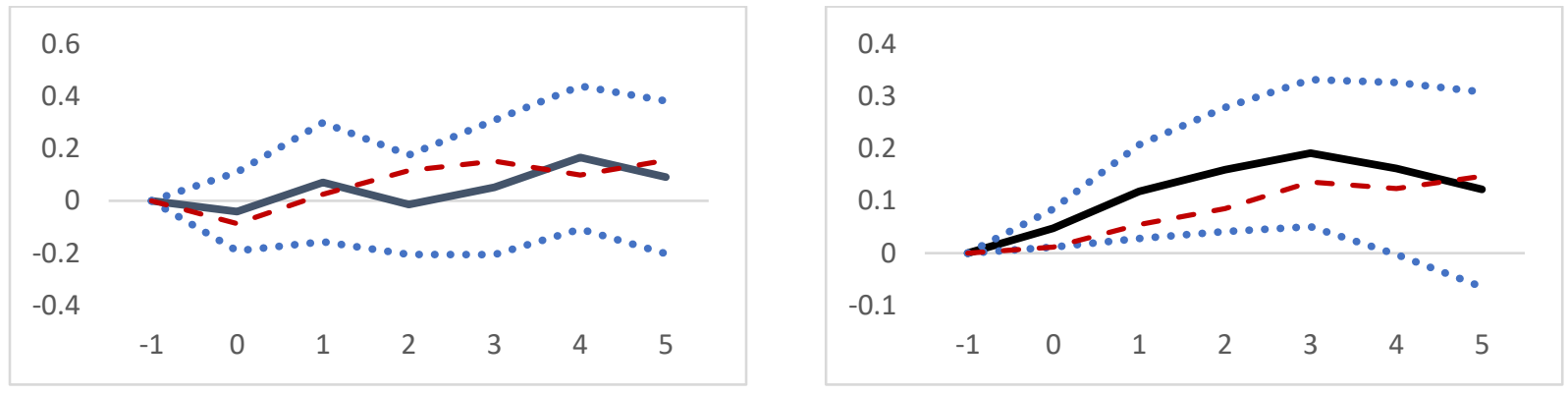

\section{Panel C. Advanced Economics}

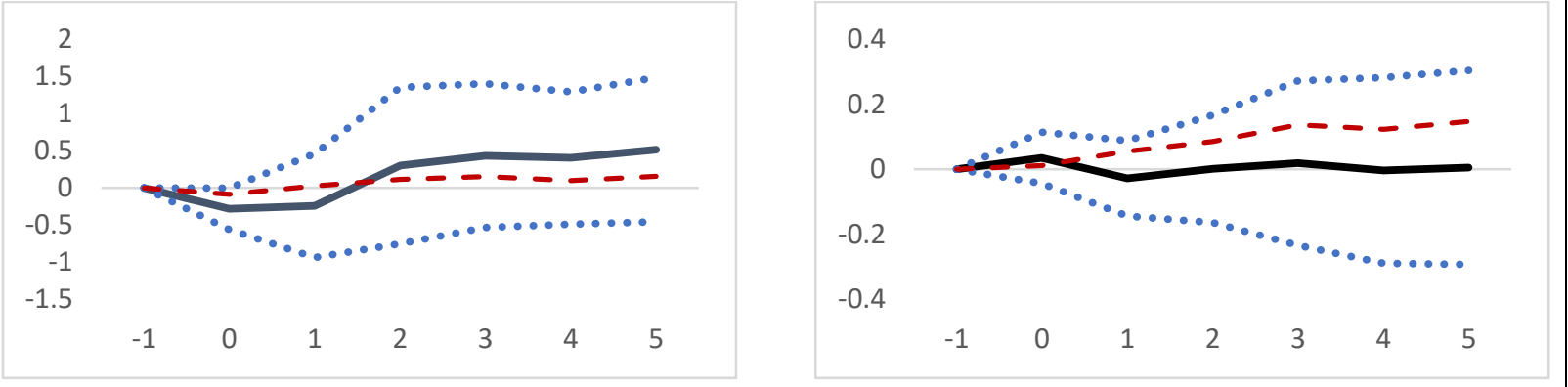

Panel D. Emerging Markets \& Developing Economies

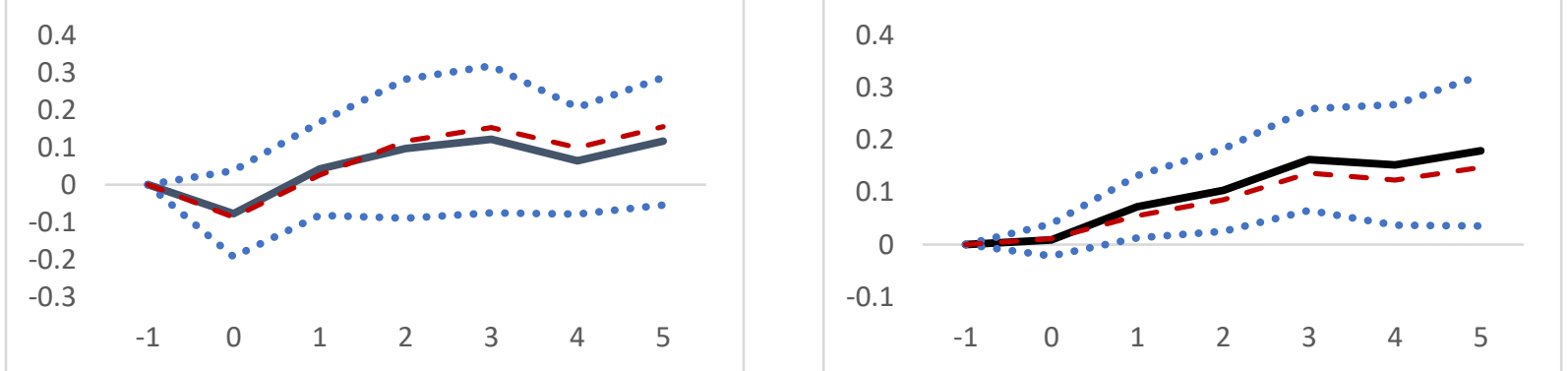

Note: The solid black line indicates the response of unemployment (inequality) to a one standard deviation increase and decrease in tariff (advanced economies and emerging markets \& developing economies); the dotted lines correspond to $90 \%$ confidence bands; estimates for Panel A and B are based on equation (2); estimates for Panel C and D are based on equation (3). Dashed red lines indicate the response of unemployment (inequality) to a one standard deviation increase in tariff in the baseline; estimates based on equation (1). The $x$-axis denotes time. $\mathrm{t}=0$ is the year of the tariff change. 


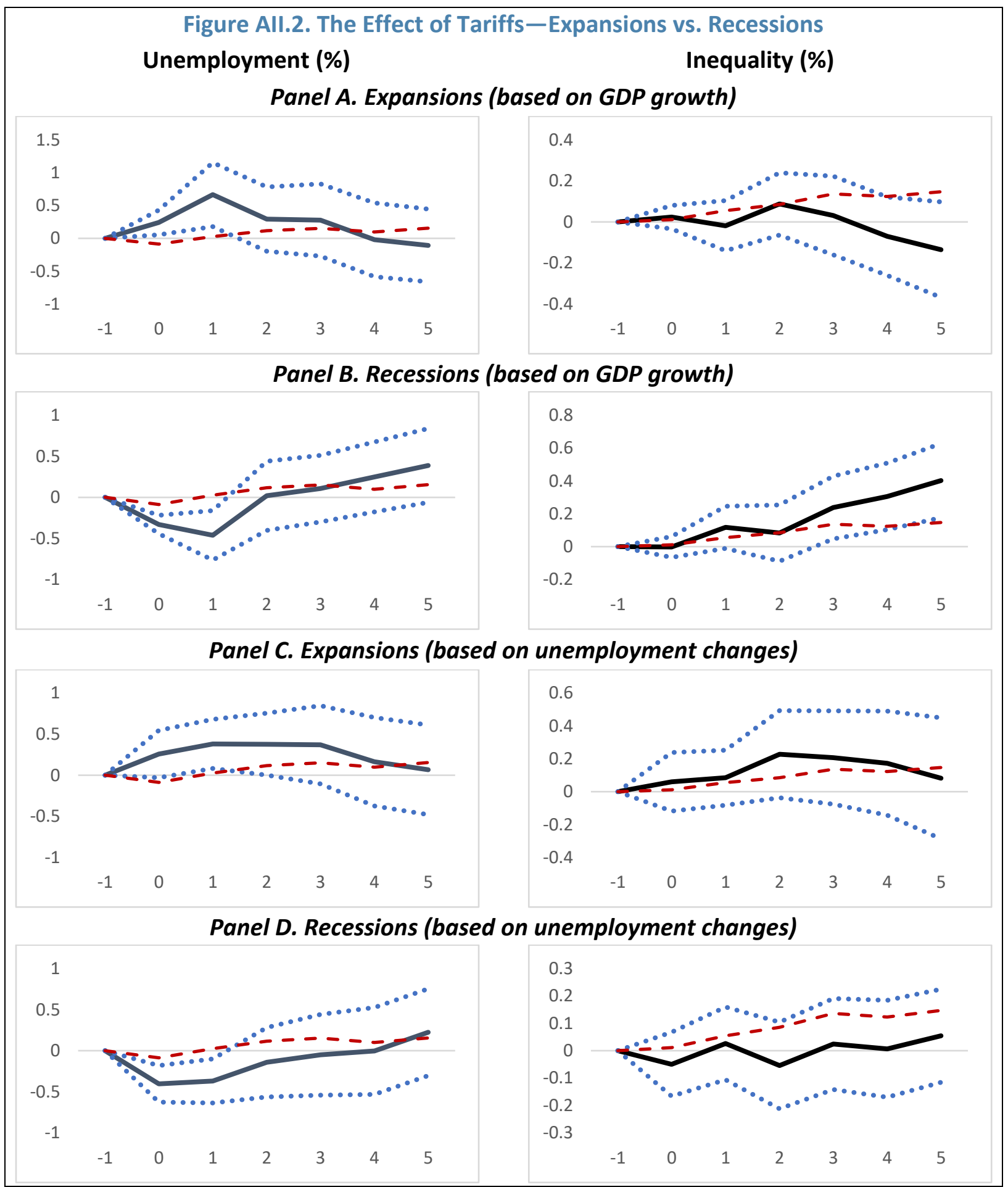

Note: The solid black line indicates the response of unemployment (inequality) to a one standard deviation increase in tariff during expansions and recessions; the dotted lines correspond to $90 \%$ confidence bands; estimates based on equation (4); for Panel A and B expansions and recessions are identified using GDP growth; for Panel $C$ and $D$ using unemployment changes. Dashed red lines indicate the response of unemployment (inequality) to a one standard deviation increase in tariff in the baseline; estimates based on equation (1). The $\mathrm{x}$-axis denotes time. $\mathrm{t}=0$ is the year of the tariff change. 


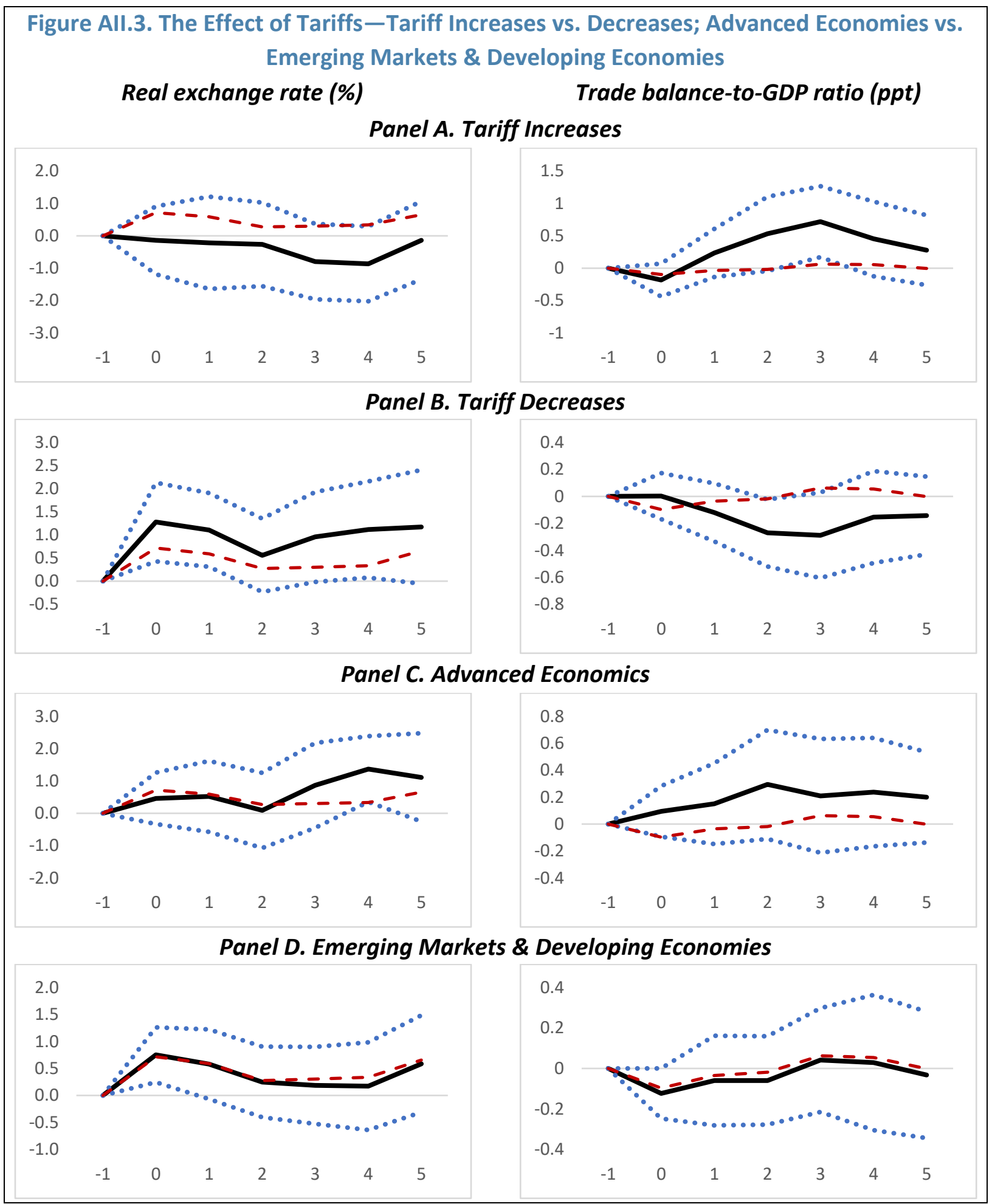

Note: The solid black line indicates the response of real exchange rate (trade balance) to a one standard deviation increase and decrease in tariff (advanced economies and emerging markets \& developing economies); the dotted lines correspond to $90 \%$ confidence bands; estimates for Panel A and B are based on equation (2); estimates for Panel C and D are based on equation (3). Dashed red lines indicate the response of real exchange rate (trade balance) to a one standard deviation increase in tariff in the baseline; estimates based on equation (1). The $x$-axis denotes time. $t=0$ is the year of the tariff change. 


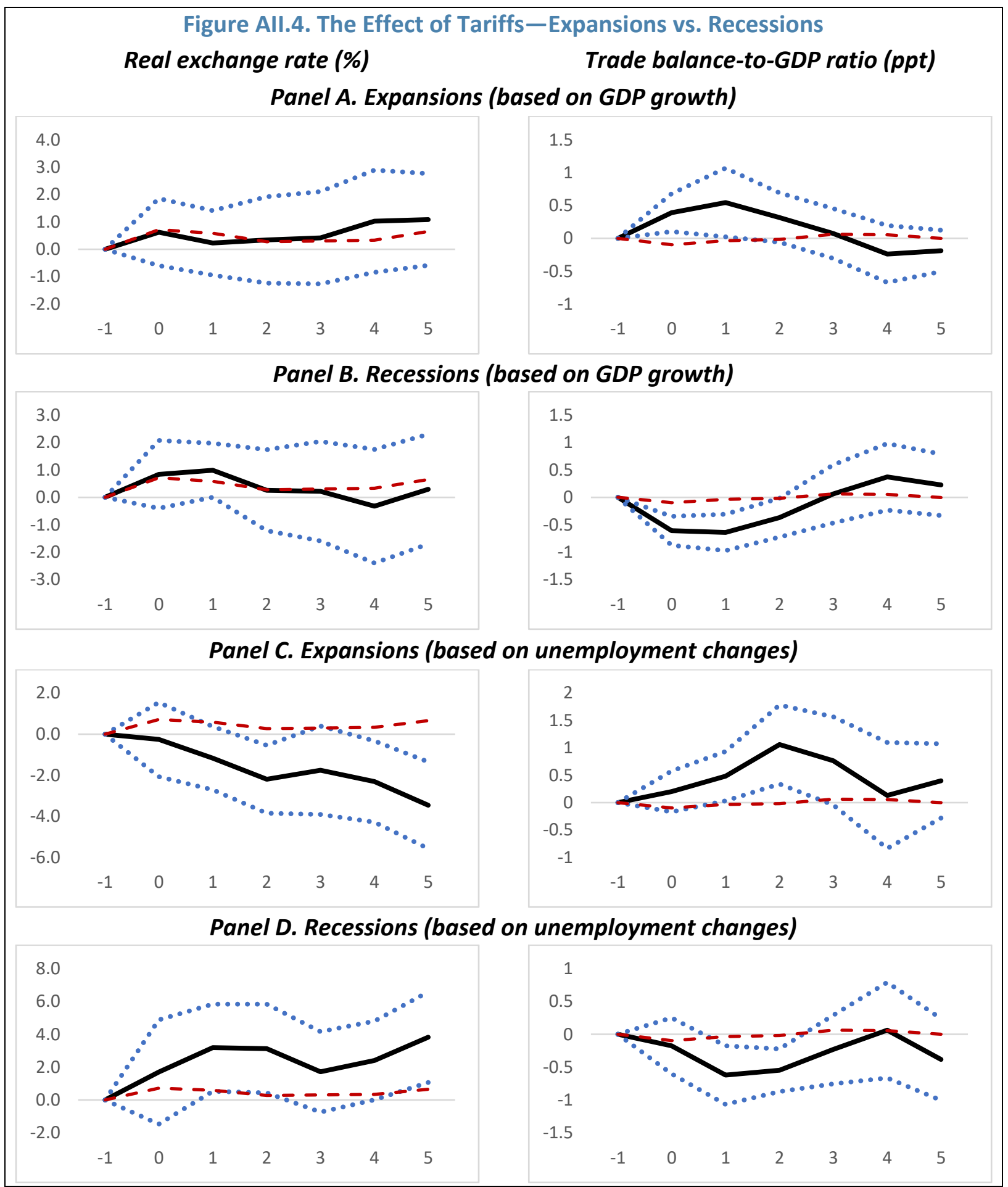

Note: The solid black line indicates the response of real exchange rate (trade balance) to a one standard deviation increase in tariff during expansions and recessions; the dotted lines correspond to $90 \%$ confidence bands; estimates based on equation (4); for Panel A and B expansions and recessions are identified using GDP growth; for Panel C and D using unemployment changes. Dashed red lines indicate the response of real exchange rate (trade balance) to a one standard deviation increase in tariff in the baseline; estimates based on equation (1). The $x$-axis denotes time. $t=0$ is the year of the tariff change. 
APPENDIX III-ROBUStNesS RESULTS FOR UNEMPLOYMENT, INEQUALITY, REAL EXCHANGE RATE, AND TRADE BALANCE

Figure Alll.1. Robustness for Unemployment

\section{Default (Figure 1)}

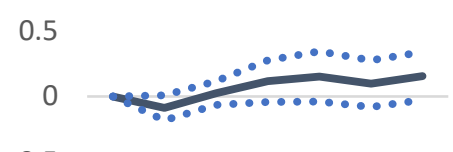

$-0.5$
Percent change of tariffs

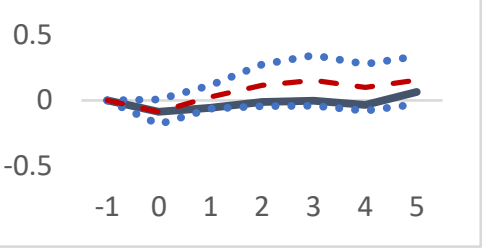

Include contemporary shocks

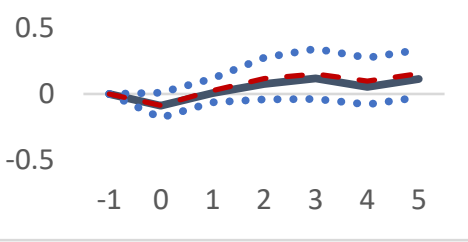

Drop series with gaps

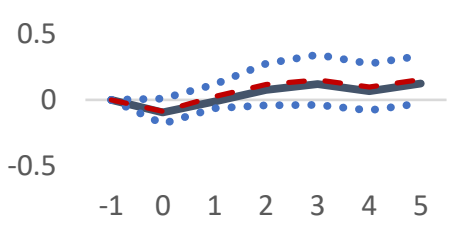

Drop outliers

0.5

0

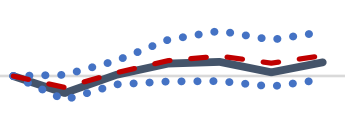

$-0.5$
Include growth forecasts

0.5

0

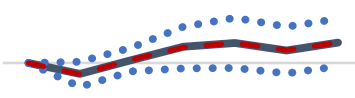

$-0.5$

$\begin{array}{lllllll}-1 & 0 & 1 & 2 & 3 & 4 & 5\end{array}$
Lag tariffs

0.5

0

$-0.5$

$\begin{array}{llllll}0 & 1 & 2 & 3 & 4 & 5\end{array}$

IV

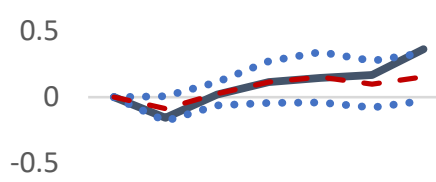

Drop small population (<1million)

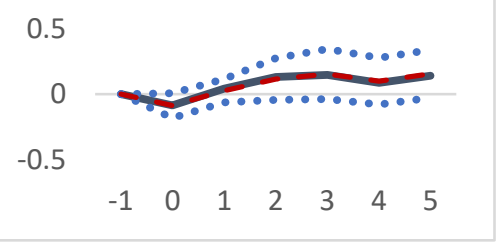

\section{Drop high tariffs (>66 percent)}

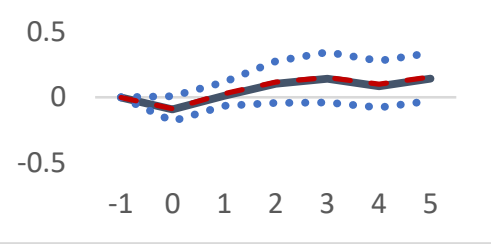

\section{Drop Americas}

0.5

0

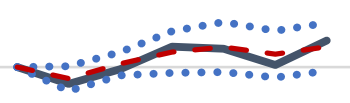

$-0.5$
Drop early years $(<1980)$

0.5

0

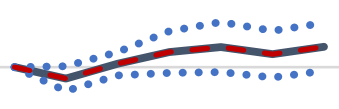

$-0.5$

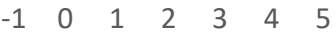

Drop high inflation (>100\%)

0.5

0

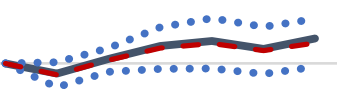

$-0.5$

$\begin{array}{lllllll}-1 & 0 & 1 & 2 & 3 & 4 & 5\end{array}$

Note: The black solid line indicates the response of unemployment to a one standard deviation increase in tariff using the scenarios described in each title of the chart. The red dotted line represents the baseline results, estimated based on equation (1). The blue dotted lines correspond to $90 \%$ confidence bands of the baseline. The $x$-axis denotes time. $t=0$ is the year of the change. 
Figure AllI.2. Robustness for Inequality

\section{Default (Figure 1)}

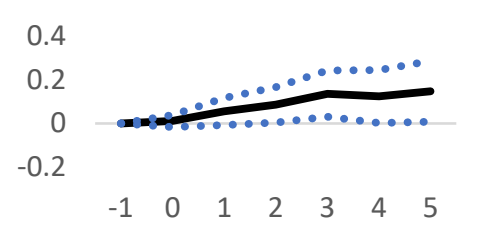

\section{Percent change of tariffs}

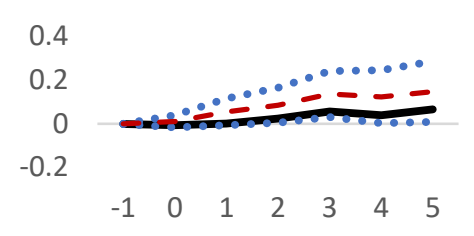

Include contemporary shocks

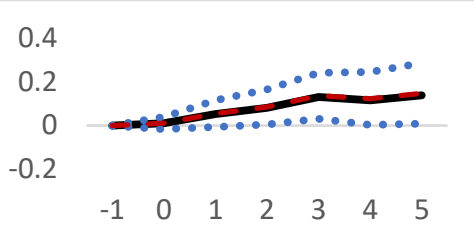

Drop series with gaps

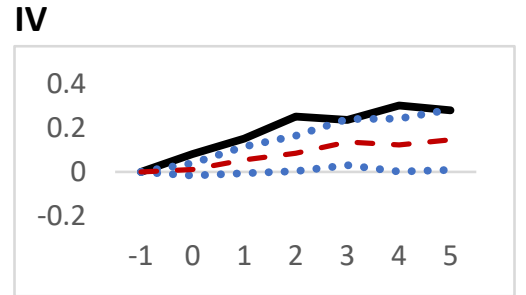

Drop small population (<1million)

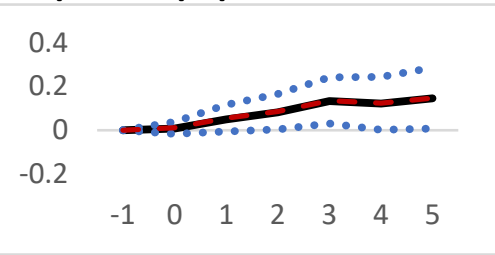

Drop high tariffs (>66 percent)

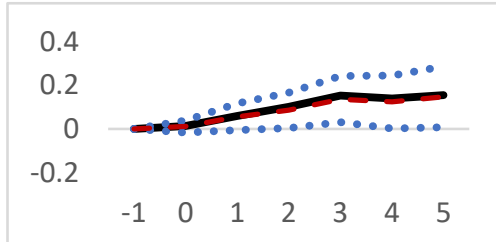

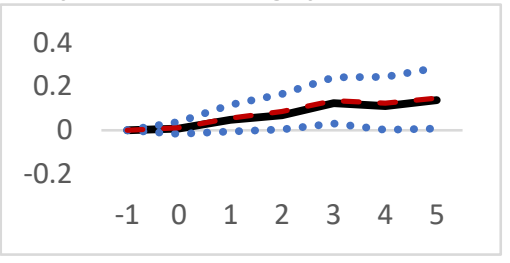

\section{Drop outliers}

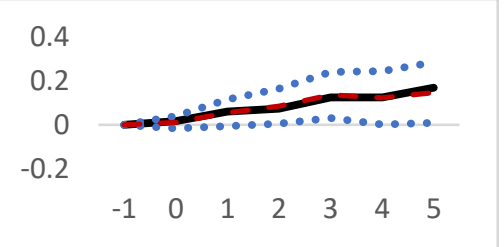

\section{Drop Americas}

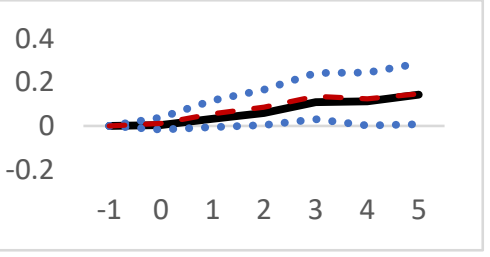

\section{Lag tariffs}

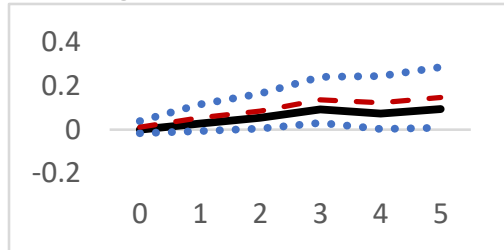

Include growth forecasts

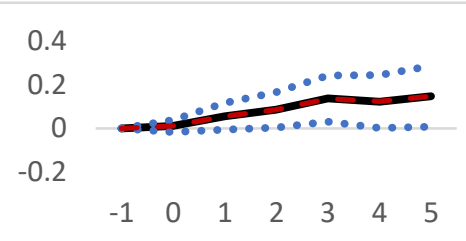

Drop high inflation (>100\%)

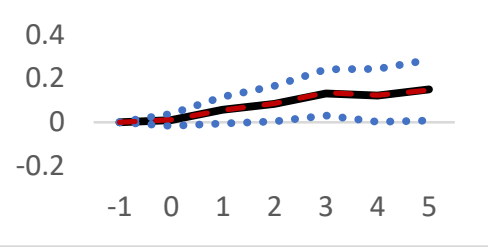

Drop early years $(<1980)$

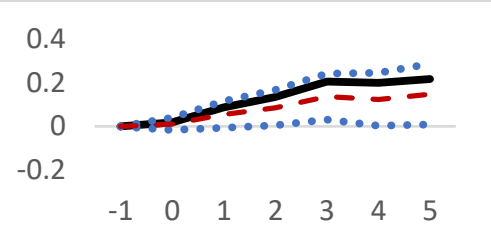

Drop Asians/Africans

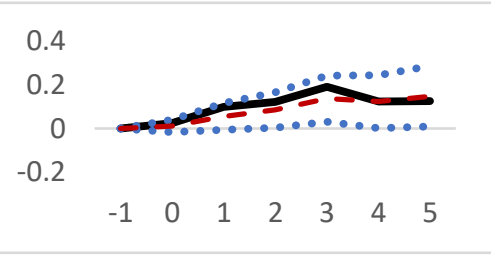

Note: The black solid line indicates the response of inequality to a one standard deviation increase in tariff using the scenarios described in each title of the chart. The red dotted line represents the baseline results, estimated based on equation (1). The blue dotted lines correspond to $90 \%$ confidence bands of the baseline. The $x$-axis denotes time. $t=0$ is the year of the change. 
Figure AlII.3. Robustness for Real Exchange Rate

Default (Figure 1)

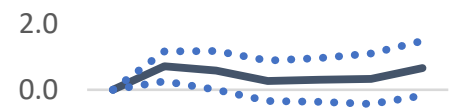

$-2.0$

$\begin{array}{lllllll}-1 & 0 & 1 & 2 & 3 & 4 & 5\end{array}$
Percent change of tariffs

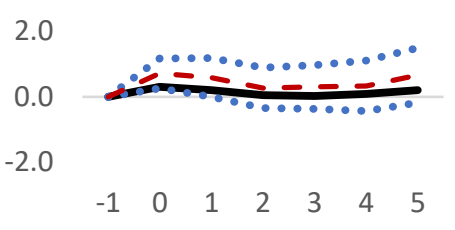

Include contemporary shocks

2.0

0.0

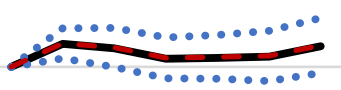

$-2.0$

$\begin{array}{lllllll}-1 & 0 & 1 & 2 & 3 & 4 & 5\end{array}$
Lag tariffs

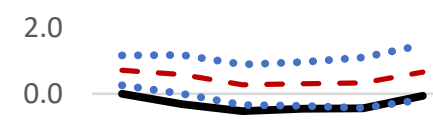

$-2.0$

$\begin{array}{llllll}0 & 1 & 2 & 3 & 4 & 5\end{array}$

Include growth forecasts

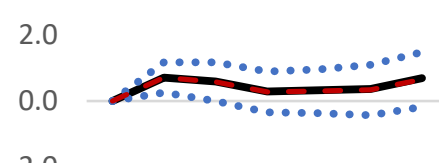

$-2.0$

$\begin{array}{lllllll}-1 & 0 & 1 & 2 & 3 & 4 & 5\end{array}$

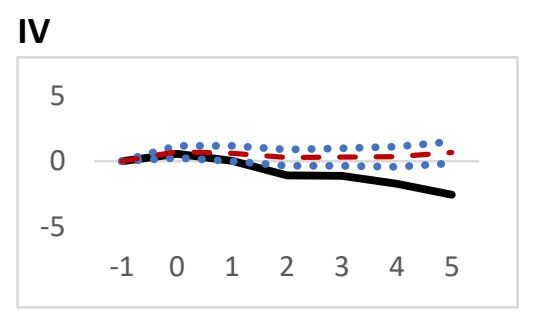

Drop series with gaps

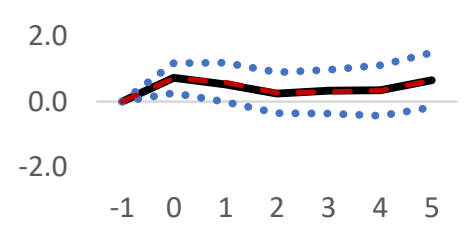

Drop outliers

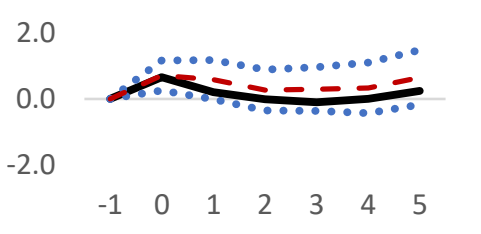

Drop Americas

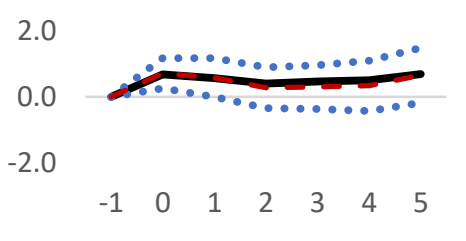

Drop high inflation (>100\%)

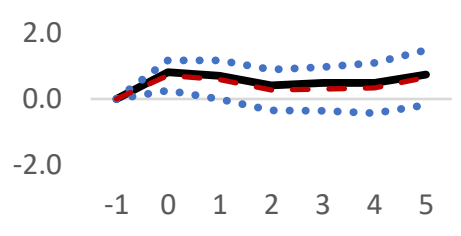

Drop early years (<1980)

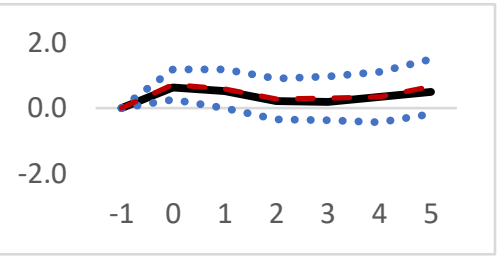

Drop Asians/Africans

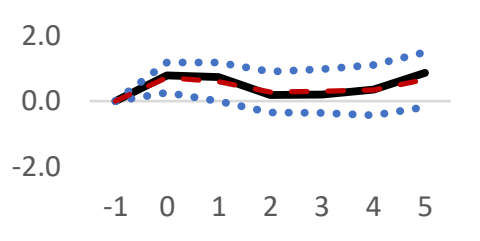

Note: The black solid line indicates the response of real exchange rate to a one standard deviation increase in tariff using the scenarios described in each title of the chart. The red dotted line represents the baseline results, estimated based on equation (1). The blue dotted lines correspond to $90 \%$ confidence bands of the baseline. The $x$-axis denotes time. $t=0$ is the year of the change. 
Figure All.4. Robustness for Trade Balance-to-GDP Ratio

Default (Figure 1)

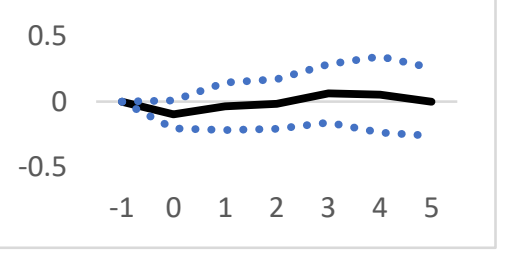

\section{VAR-style}

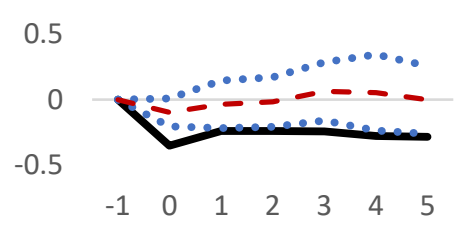

IV

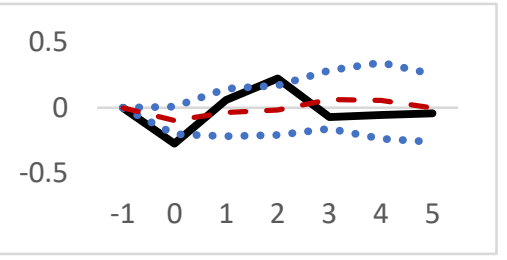

Drop small population (<1million)

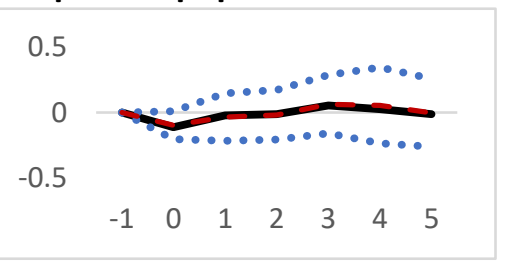

Drop high tariffs (>66 percent)

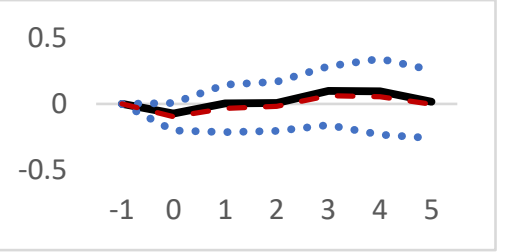

Percent change of tariffs

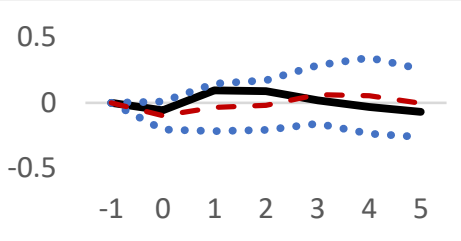

Include contemporary shocks

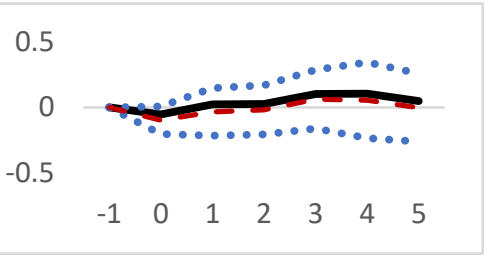

Drop series with gaps

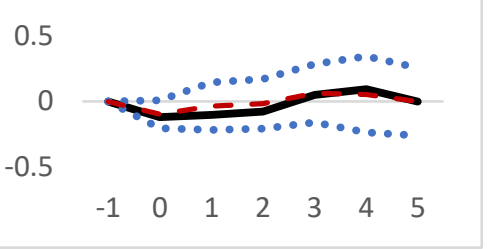

Drop outliers

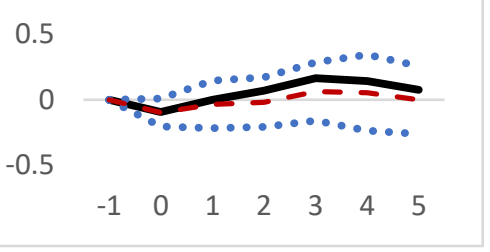

Drop Americas

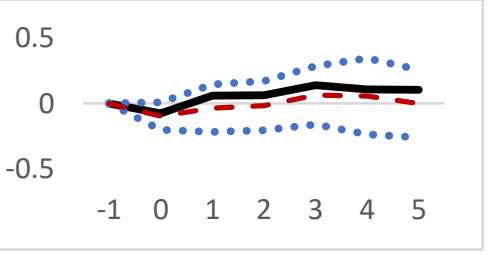

Lag tariffs

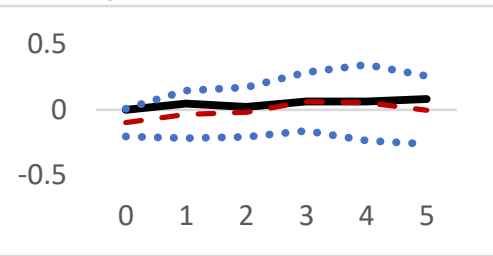

Include growth forecasts

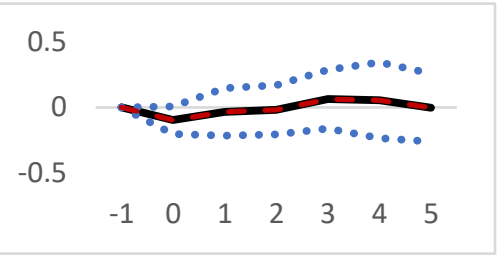

Drop high inflation (>100\%)

0.5

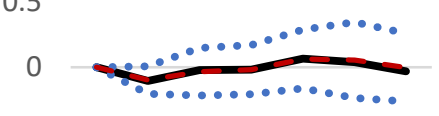

$-0.5$

$\begin{array}{lllllll}-1 & 0 & 1 & 2 & 3 & 4 & 5\end{array}$

\section{Drop early years (<1980)}

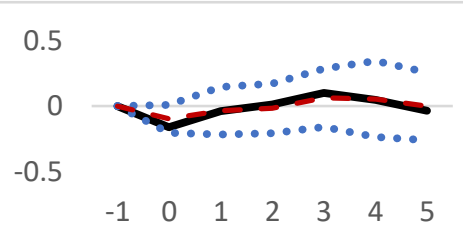

Drop Asians/Africans

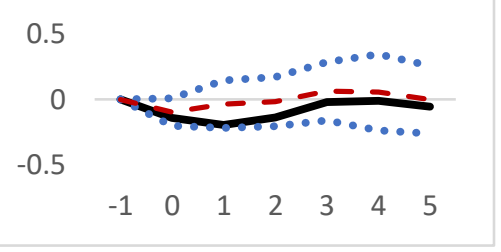

Note: The black solid line indicates the response of trade balance to a one standard deviation increase in tariff using the scenarios described in each title of the chart. The red dotted line represents the baseline results, estimated based on equation (1). The blue dotted lines correspond to $90 \%$ confidence bands of the baseline. The $\mathrm{x}$-axis denotes time. $\mathrm{t}=0$ is the year of the change. 


\section{APPENDIX IV—RESULTS FOR CONSUMPTION AND INFLATION}

Figure AIV.1: Baseline and Selected Asymmetric Results for Consumption and Inflation

Panel A: Baseline for Consumption

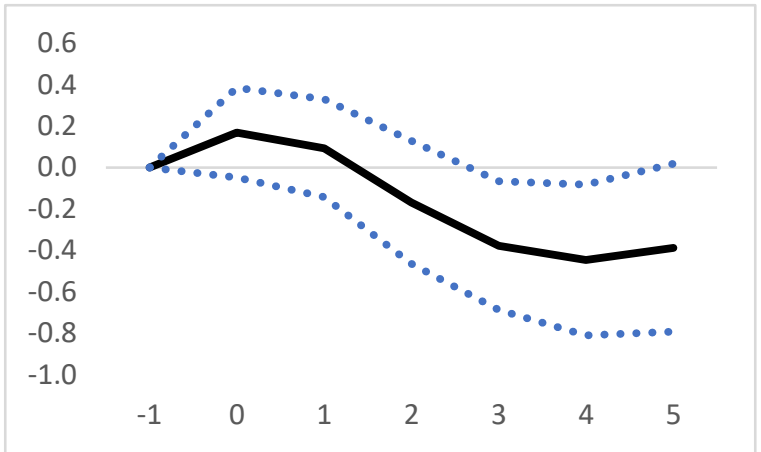

The Asymmetric Effect on Consumption

Panel C: Tariff Increases

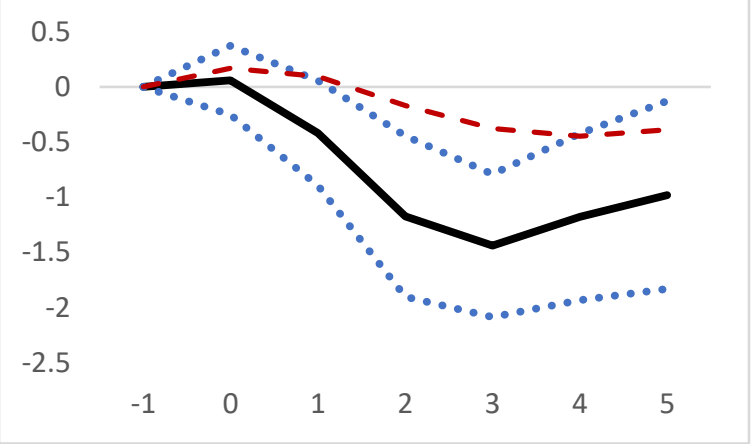

The Asymmetric Effect on Inflation

Panel E: Expansions (based on GDP growth)

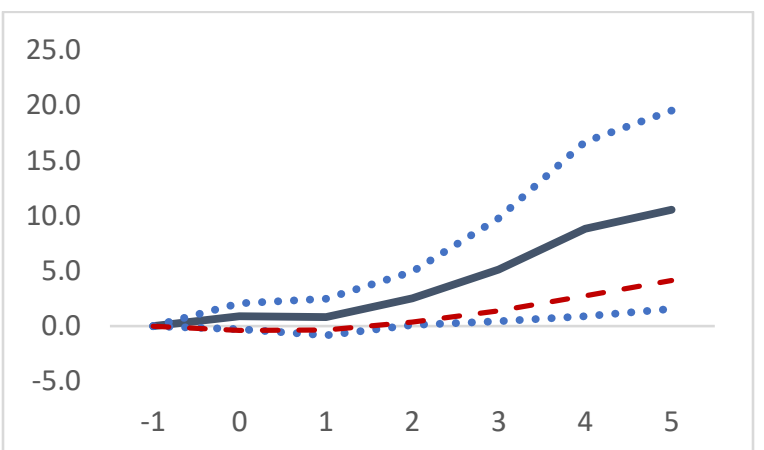

Panel B: Baseline for Inflation

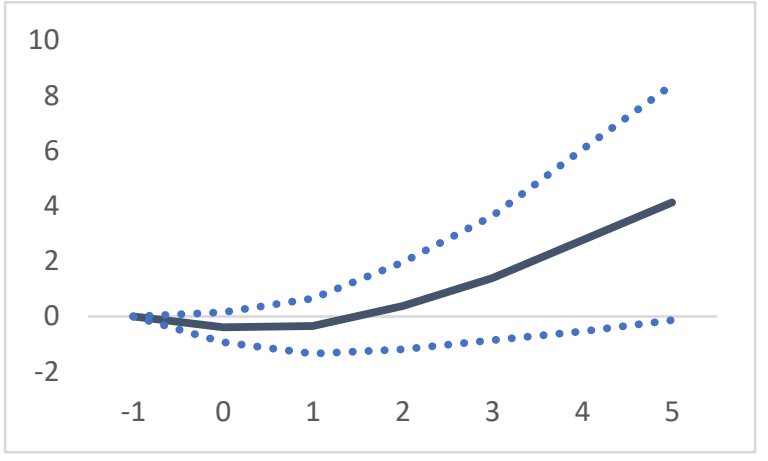

Panel D: Tariff Decreases

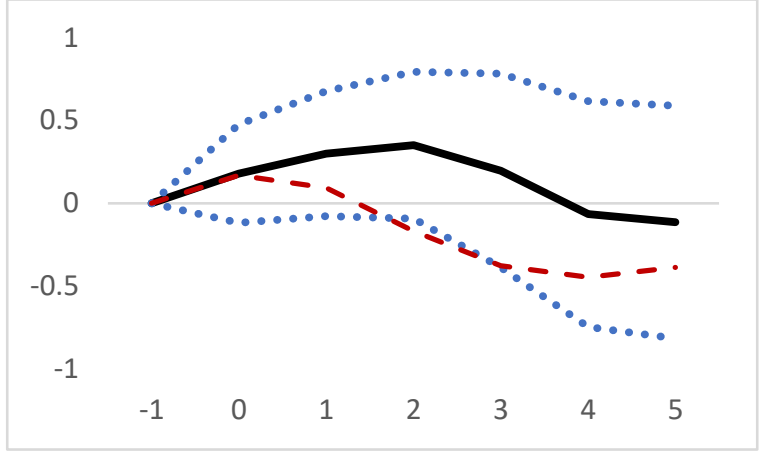

Panel F: Recessions (based on GDP growth)

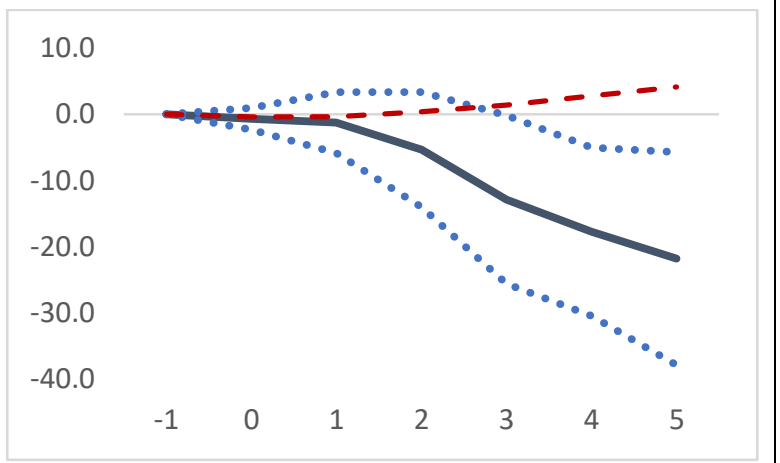

Note: The solid black line indicates the response of consumption (inflation) to a one standard deviation increase in tariff; the dotted lines correspond to $90 \%$ confidence bands; estimates for Panel A and B are based on equation (1); estimates for Panel $C$ and $D$ are based on equation (2); estimates for Panel $E$ and $F$ are based on equation (4). Dashed red lines indicate the response of consumption (inflation) to a one standard deviation increase in tariff in the baseline; estimates based on equation (1). The $x$-axis denotes time. $t=0$ is the year of the tariff change. 


\section{APPEndix V-Instrumental Variable}

To address the endogeneity concerns further, we implement an instrumental variable (IV) approach, using as an instrument the weighted-average of changes in the tariff in major (top 5) trading-partner countries, where the weights are determined by the strength of trade linkages with other countries. Specifically, the instrument is computed as follows:

$I_{i, t}=\sum_{j=1,5(j \neq i)} \Delta T_{j, t} w_{i, j, t}$

where $I_{i, t}$ is the instrument of tariff for country $i$ at time $t ; \Delta T_{j, t}$ is the change in the tariff for country $j$ (up to the 5 largest trading partners) at time $t$; and $w_{i, j, t}$ is the share of total exports and imports between country $\mathrm{i}$ and country $\mathrm{j}$ in the total exports and imports for country $i: \frac{\text { Export }_{i, j, t}+\text { Import }_{i, j, t}}{\text { Export }_{i, t}+\text { Import }_{i, t}}$.

The first and second stage estimates for the output effect suggest that this instrument is "strong" and statistically significant (see Tables AV.1 and AV.2). In particular, The Kleibergen-Paap rk Wald F statistic - which is equivalent to the F-effective statistics for non-homoskedastic error in case of one endogenous variable and one instrument (Andrews, Stock and Su, 2018) - for each horizon of the IRF is higher than the associated Stock-Yogo critical values. ${ }^{26}$

In addition, we can plausibly consider the instrument to be exogenous, since changes in the tariff in major (top 5) trading-partner countries are unlikely to be correlated with the error term of Equation (1), once we control for lagged changes in domestic macroeconomic variables (output, real exchange rates, tariff and trade balance). We perform exclusion-restriction tests and find that tariff changes in major trading partners do not have any effect on output or other outcome variables of interest in country $i$ if not through tariff changes in country i. From a theoretical point of view, another concern is that 
the instrument could be correlated with the error term to the extent that changes in tariff rates in main large trading partners could affect domestic output through contemporaneous changes in the real exchange rate. To address this issue, we modify the equation to control for the contemporaneous changes in other control variables, including the real exchange rates. The results are robust to this specification and very similar to those presented in Figure 5.

Table AV.1. First Stage estimates of Change in Tariffs on the Instrument (the weightedaverage of changes in the tariff in major (top 5) trading-partner countries)

\begin{tabular}{|c|c|}
\hline Instrument (t) & $\begin{array}{c}0.446 * * * \\
(3.97)\end{array}$ \\
\hline Change in Tariff ${ }_{(\mathrm{t}-1)}$ & $\begin{array}{c}-0.160 * * \\
(-9.79)\end{array}$ \\
\hline Change in Tariff ${ }_{(\mathrm{t}-2)}$ & $\begin{array}{c}-0.044 * * * \\
(-2.82)\end{array}$ \\
\hline Output growth (t-1) & $\begin{array}{l}-1.400 \\
(-0.94)\end{array}$ \\
\hline Output growth (t-2) & $\begin{array}{l}0.585 \\
(0.40)\end{array}$ \\
\hline Change in REER $(\mathrm{t}-1)$ & $\begin{array}{c}0.001 \\
90.09)\end{array}$ \\
\hline Change in REER $(\mathrm{t}-2)$ & $\begin{array}{l}0.005 \\
(0.58)\end{array}$ \\
\hline Change in Trade Balance $(\mathrm{t}-1)$ & $\begin{array}{l}0.332 \\
(0.64)\end{array}$ \\
\hline Change in Trade Balance $(\mathrm{t}-2)$ & $\begin{array}{l}0.031 \\
(0.06)\end{array}$ \\
\hline $\mathrm{N}$ & 3717 \\
\hline$R^{2}$ & 0.08 \\
\hline
\end{tabular}


Table AV.2. Second Stage estimates of Output on the Change in Tariff Instrumented

\begin{tabular}{|c|c|c|c|c|c|c|}
\hline & $K=0$ & $K=1$ & $K=2$ & $K=3$ & $K=4$ & $K=5$ \\
\hline Change in Tariff_Instumented (t-1) & $\begin{array}{l}0.503^{*} \\
(1.78)\end{array}$ & $\begin{array}{l}-0.001 \\
(-0.00)\end{array}$ & $\begin{array}{l}-0.785 \\
(-1.07)\end{array}$ & $\begin{array}{l}-0.770 \\
(-1.29)\end{array}$ & $\begin{array}{c}-1.295^{* *} \\
(-1.97)\end{array}$ & $\begin{array}{c}-1.235^{* *} \\
(-1.97)\end{array}$ \\
\hline Change in Tariff $(\mathrm{t}-1)$ & $\begin{array}{l}0.069 \\
(1.37)\end{array}$ & $\begin{array}{l}-0.044 \\
(-0.60)\end{array}$ & $\begin{array}{l}-0.160 \\
(-1.53)\end{array}$ & $\begin{array}{c}-0.197^{* *} \\
(-2.00)\end{array}$ & $\begin{array}{c}-0.280^{* * *} \\
(-2.45)\end{array}$ & $\begin{array}{c}-0.280 * * * \\
(-2.47)\end{array}$ \\
\hline Change in Tariff $(\mathrm{t}-2)$ & $\begin{array}{l}-0.011 \\
(-0.64)\end{array}$ & $\begin{array}{l}-0.036 \\
(-1.49)\end{array}$ & $\begin{array}{c}-0.106^{* * *} \\
(-2.71)\end{array}$ & $\begin{array}{c}-0.125^{* * *} \\
(-3.46)\end{array}$ & $\begin{array}{c}-0.144 * * * \\
(-4.09)\end{array}$ & $\begin{array}{c}-0.170 * * * \\
(-6.74)\end{array}$ \\
\hline Output growth (t-1) & $\begin{array}{c}0.275^{* * *} \\
(7.66)\end{array}$ & $\begin{array}{c}0.329 * * * \\
(8.94)\end{array}$ & $\begin{array}{c}0.351^{* * *} \\
(7.81)\end{array}$ & $\begin{array}{c}0.332^{* * *} \\
(5.34)\end{array}$ & $\begin{array}{c}0.290 * * * \\
(3.62)\end{array}$ & $\begin{array}{c}0.277^{* * *} \\
(3.06)\end{array}$ \\
\hline Output growth (t-2) & $\begin{array}{l}0.005 \\
(0.19)\end{array}$ & $\begin{array}{l}0.035 \\
(0.66)\end{array}$ & $\begin{array}{l}0.017 \\
(0.20)\end{array}$ & $\begin{array}{l}-0.007 \\
(-0.07)\end{array}$ & $\begin{array}{l}-0.026 \\
(-0.26)\end{array}$ & $\begin{array}{l}-0.025 \\
(-0.25)\end{array}$ \\
\hline Change in REER (t-1) & $\begin{array}{c}-0.028^{*} \\
(-1.82)\end{array}$ & $\begin{array}{c}-0.069 * * * \\
(-4.29)\end{array}$ & $\begin{array}{c}-0.099 * * * \\
(-4.59)\end{array}$ & $\begin{array}{c}-0.080 * * \\
(-2.27)\end{array}$ & $\begin{array}{l}-0.038 \\
(-0.74)\end{array}$ & $\begin{array}{l}-0.013 \\
(-0.22)\end{array}$ \\
\hline Change in REER (t-2) & $\begin{array}{l}-0.027 \\
(-1.39)\end{array}$ & $\begin{array}{c}-0.055^{*} \\
(-1.75)\end{array}$ & $\begin{array}{l}-0.034 \\
(-0.69)\end{array}$ & $\begin{array}{l}0.010 \\
(0.15)\end{array}$ & $\begin{array}{l}0.033 \\
(0.42)\end{array}$ & $\begin{array}{l}0.051 \\
(0.68)\end{array}$ \\
\hline Change in Trade Balance (t-1) & $\begin{array}{c}-1.511^{* *} \\
(-2.52)\end{array}$ & $\begin{array}{c}-2.749 * * \\
(-2.43)\end{array}$ & $\begin{array}{c}-3.598^{*} \\
(-1.76)\end{array}$ & $\begin{array}{c}-3.611^{*} \\
(-1.86)\end{array}$ & $\begin{array}{c}-2.766^{*} \\
(-1.75)\end{array}$ & $\begin{array}{l}-1.814 \\
(-1.06)\end{array}$ \\
\hline Change in Trade Balance $(t-2)$ & $\begin{array}{l}-1.001 * \\
(-1.84)\end{array}$ & $\begin{array}{c}-2.298^{* *} \\
(-2.13)\end{array}$ & $\begin{array}{l}-2.221 \\
(-1.50)\end{array}$ & $\begin{array}{l}-1.231 \\
(-0.61)\end{array}$ & $\begin{array}{l}-0.013 \\
(-0.06)\end{array}$ & $\begin{array}{l}1.472 \\
(0.75)\end{array}$ \\
\hline N & 3716 & 3622 & 3502 & 3387 & 3265 & 3145 \\
\hline $\begin{array}{l}\text { KP F-statistics } \\
\text { (Stock-Yogo critical value 10\%) }\end{array}$ & $\begin{array}{l}21.270 \\
(16.38)\end{array}$ & $\begin{array}{l}24.834 \\
(16.38)\end{array}$ & $\begin{array}{l}22.737 \\
(16.38)\end{array}$ & $\begin{array}{l}21.795 \\
(16.38)\end{array}$ & $\begin{array}{l}25.536 \\
(16.38)\end{array}$ & $\begin{array}{l}25.297 \\
(16.38)\end{array}$ \\
\hline
\end{tabular}

Note: t-statistic based on Driscoll-Kraay standard errors. $* * * * *, *$ denote significance at 1,5 and 10 percent, respectively. Instrument computed as the weighted-average of changes in the tariff in major (top 5) tradingpartner countries. Estimates based on equation (1). 


\section{Endnotes}

${ }^{1}$ For example, see the survey on free trade in Initiative on Global Markets (University of Chicago Booth School of Business): http://www.igmchicago.org/surveys/free-trade.

${ }^{2}$ We also try to account for potential endogeneity via an instrumental variable strategy, using changes in tariffs in major large trading partners to create instruments.

${ }^{3}$ If changes in tariffs are correlated with changes in non-tariff barriers (NTBs), there may be a concern with omitted variable bias. To test this, we run panel regressions on the relationship between three different measures of NTBs (anti-dumping cases initiated, safeguards, and WTO disputes) and changes in tariffs, controlling for country- and time-fixed effects (as in our estimation framework described in equation 1). We do not find evidence of any strong correlation, mitigating this concern in our set-up. However, the results should be taken with a pinch of salt since NTBs are difficult to measure and data is scarce for this exercise.

${ }^{4}$ Kehoe (2003) compares the predictions of three ex-ante CGE studies of NAFTA with observed outcomes and concludes that trade increases in most sectors surpassed the predictions more than ten-fold. Corcos et. al (2012) find same results for the EU.

${ }^{5}$ Since the set of control variables includes lags of output growth as well as the real exchange rate and trade balance, this approach is equivalent to a VAR approach in which tariff shocks do not respond to shocks in other variables within a year. We relax this assumption later as a robustness check.

${ }^{6}$ While the original INDSTAT 2 database includes 23 manufacturing industries, exclude the "manufacture of recycling" industry due to insufficient observations.

${ }^{7}$ The average and standard deviation of the change in the tariff rate in our sample are -0.4 and 3.6 percentage points, respectively. Tariff changes range from -52.0 to 41.0 percentage points.

${ }^{8}$ Table 6 tabulates the underlying regression results.

${ }^{9}$ Employment increases by about 0.5 percent but the effect is not statistically significant.

${ }^{10}$ This result is consistent with evidence in Jaumotte, Lall and Papageorgiou (2013) who find that trade openness is associated with lower income inequality. While more work is needed to understand the distributional effects of tariffs, we believe that the increase in unemployment is a potentially important channel. Another possibility is that rent-seeking means that protectionism benefits more the rich than the poor.

${ }^{11}$ Using a multi-country, multi-sector, multi-factor model of world production and trade with global inputoutput linkages, Bonadio and Levchenko (2018) show that revoking NAFTA would reduce US welfare by about 0.2 percent, and Canadian and Mexican welfare by about 2 percent, with a real wage decline of 0.3 in the US and 1.7 in Canada and Mexico.

${ }^{12}$ See Appendix I for some examples of major tariff increases in our sample.

${ }^{13}$ Around 28 percent of our sample observations consist of tariff changes for advanced economies (with a mean of -.3 percentage points and standard deviation of 2.2) and 65 percent of the observations consist of tariff changes for other countries (with mean of -.3 and standard deviation of 4.1). While tariff changes have been less frequent in rich countries, the average magnitude of the changes is similar across the samples. 
Similarly, we do not observe significantly differences in the ratio of positive-to-negative changes between AEs (65 percent) and non-AEs (75 percent).

${ }^{14}$ This approach is equivalent to the smooth transition autoregressive model developed by Granger and Terävistra (1993). The results are robust different value of $\theta$, and to substitute $F\left(z_{i t}\right)$ with a dummy variable which takes value for $F\left(z_{i t}\right)$ greater than 0.5 .

${ }^{15}$ In line with Rose (2013), we find no statistically significant correlation between changes in tariffs and the measure of state of economy used in the paper. In particular, the correlation between changes in tariffs and the smooth transition function $F\left(z_{i t}\right)$ is -0.001 .

${ }^{16}$ See Figures in Appendix II for equivalent results for unemployment, inequality, real exchange rate and trade balance.

${ }^{17}$ In addition to the robustness checks described in detail below, we run a version where the estimations include observations with trade balance between +/-50 percent of GDP given some of the extreme movements in this variable. Our baseline results are robust to this specification.

18 Analogous results for the other variables of interest (unemployment, inequality, the real exchange rate and the trade balance) are reported in Figures AllI, 1-4 of the Appendix III; they demonstrate the basic insensitivity of our baseline results.

${ }^{19}$ The results are robust to alternative orderings.

${ }^{20}$ Specifically, we control for contemporaneous changes in the trade balance and real exchange rate for the regressions on output, productivity, unemployment and inequality. For the regression on trade balance (real exchange rate) we control only for simultaneous changes in the real exchange rate (trade balance).

${ }^{21}$ We have also modified equation (1) by allowing all explanatory variables (including changes in the tariff) to enter with a lag.

${ }^{22}$ The Kleibergen-Paap rk Wald F statistic for each horizon of the IRF is always higher than the associated Stock-Yogo critical values.

${ }^{23}$ From a theoretical point of view, another concern is that the instrument could be correlated with the error term to the extent that changes in tariff rates in main large trading partners could affect domestic output through contemporaneous changes in the real exchange rate. To address this issue, we modify the equation to control for the contemporaneous changes in other control variables, including the real exchange rates. The results are robust to this specification and very similar to those presented in Figure 5.

${ }^{24}$ Similar results are obtained when top and bottom $5^{\text {th }}$ percentiles of the same distribution are considered.

${ }^{25}$ The result that input tariffs have a more detrimental output effect than output tariffs is consistent with previous empirical work examining the effect of input and output tariffs at the macro (e.g., Ahn et al. 2016) and at the firm level (e.g. Amiti and Konings 2007).

${ }^{26}$ Similar results are also obtained for productivity. 